\title{
Anais do $1^{\circ}$ Congresso Online de Otorrinolaringologia
}

\section{Rio-Minas}

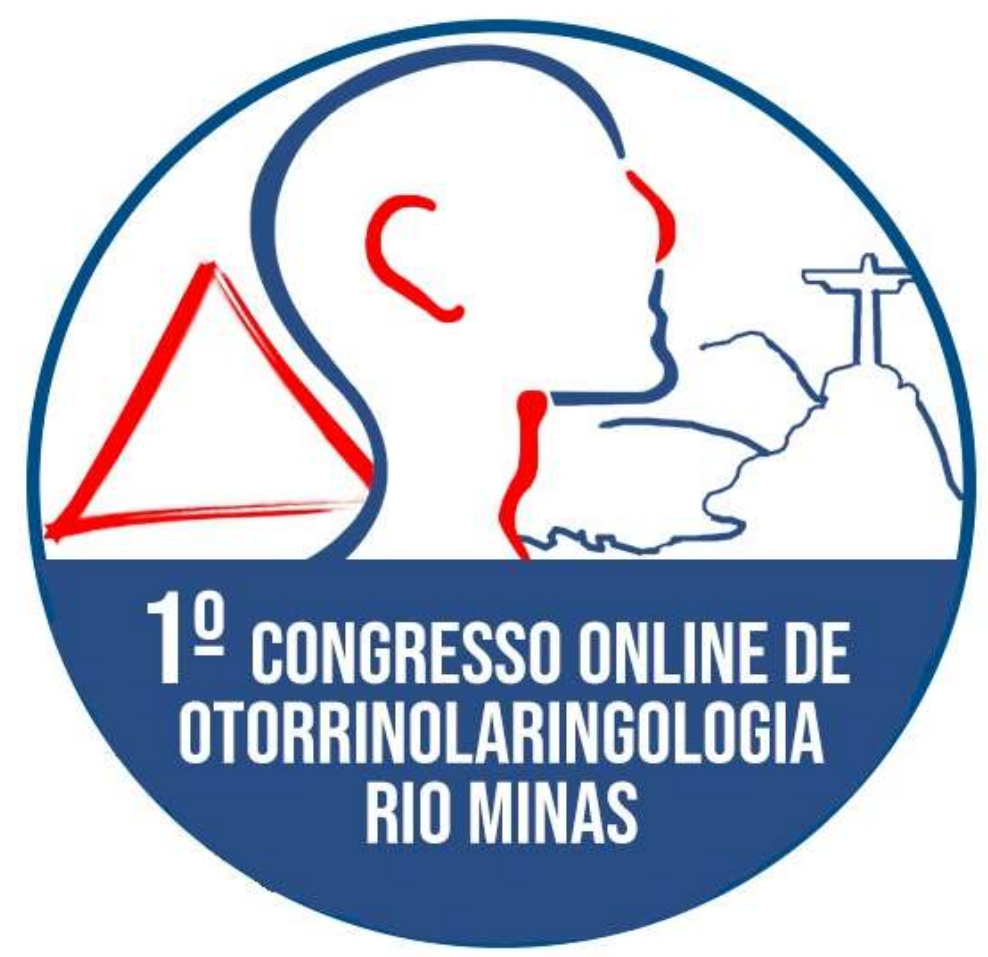

Apoio:

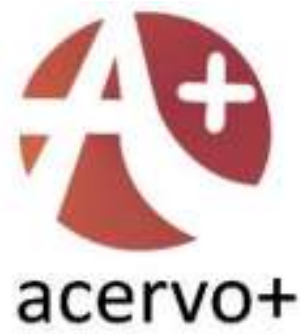

Eventos

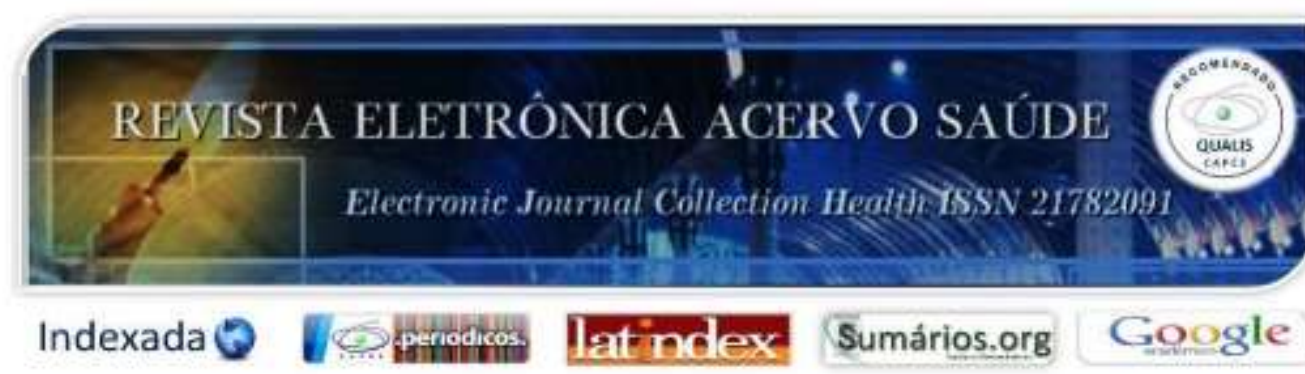




\section{SUMÁRIO}

SOBRE O EVENTO.

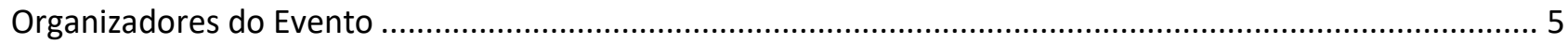

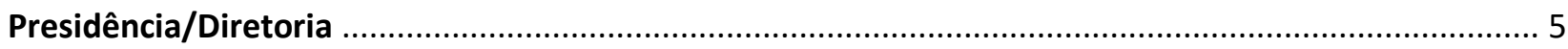

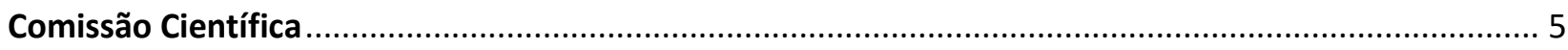

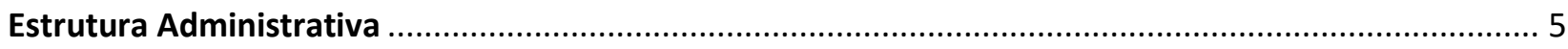

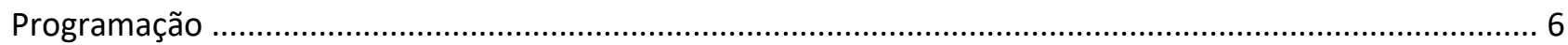

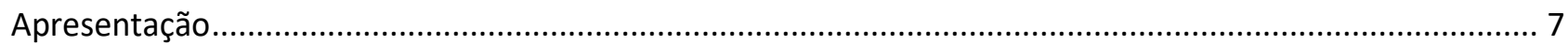

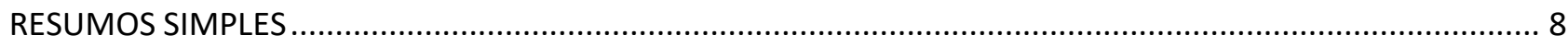

Aspectos do manejo da Apneia Obstrutiva do Sono em crianças com Síndrome de Down ....................... 8

Sonolência Excessiva Diurna em Estudantes de Medicina: uma revisão sistemática ................................. 10

Doença Falciforme e Surdez: Uma revisão sobre a Perda Auditiva Neurossensorial em crianças ............. 12

Tratamento da Otite Média Aguda por antibioticoterapia em crianças menores de três anos ................. 14

Disfonia Ocupacional em Professores e Sintomatologia Associada ......................................................... 16

Angiofibroma nasal juvenil: características tumorais e tratamento ....................................................... 18

Tratamento da Síndrome da Apneia Obstrutiva do Sono através de cirurgia ortognática ........................ 20

Correlação entre Rinite, Gestação e o Período Pós-Parto....................................................................... 22

Eficácia da Manobra de Epley no Tratamento da Vertigem Posicional Paroxística Benigna ..................... 24

Tratamento Cirúrgico versus Tratamento Conservador em Leucoplasia de Pregas Vocais ....................... 26

Associação entre infecção pelo HPV e o câncer de cavidade oral e orofaringe.......................................... 28

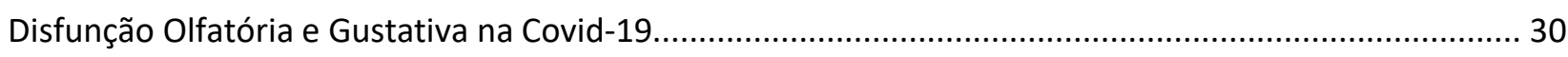

Riscos da adenotonsilectomia e adenotonsilotomia em pacientes pediátricos ....................................... 32

Eficácia do uso de pregabalina no controle da dor no pós-operatório em cirurgias cérvicofaciais: uma

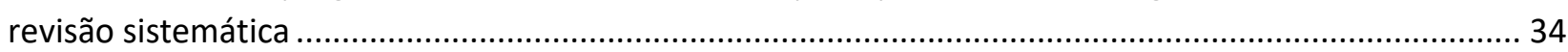

Vertigem Paroxística Benigna da Infância como precursora de enxaqueca em adolescentes e adultos ... 36

Prevenção da perda auditiva induzida por ruído (PAIR) ocupacional ..................................................... 38

Manejo Clínico de Tosse Aguda em Bebês e Crianças............................................................................ 40

Narcolepsia: Uso de Oxibato de Sódio na população pediátrica - Revisão Sistemática............................ 42

Perda auditiva induzida por ruídos e sua nocividade no ambiente de trabalho: uma revisão sistemática da

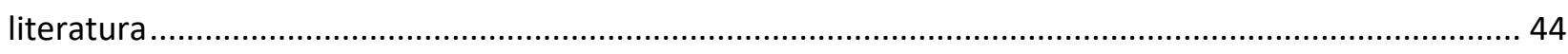

Um novo olhar sobre a surdez súbita: uma revisão sistemática da literatura......................................... 46

Manifestações Clínicas do Refluxo Laringofaríngeo: uma revisão sistemática ........................................ 48

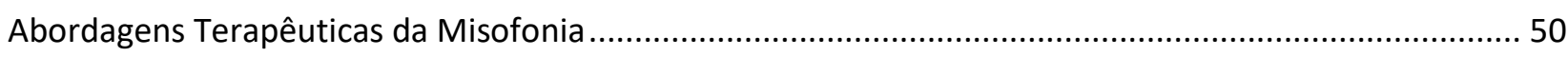


Abordagem Terapêutica com Dupilumab em Pacientes com Rinossinusite Crônica Associada à Polipose Nasal.....

Comparação entre a Eficácia do CPAP e do MAD no Tratamento Clínico da SAOS ...

Eficácia da Faringoplastia Lateral como Modalidade Terapêutica da Síndrome de Apneia Obstrutiva do Sono.

Análise do Tratamento com Laser na Papilomatose Laríngea Recorrente 60

Efeitos do Treinamento dos Músculos Respiratórios no Tratamento da Apneia Obstrutiva do Sono: Uma Revisão Sistemática

A relação do desvio de septo com a rinossinusite crônica e com a gravidade dos sintomas de obstrução nasal

Uso de Mamadeira Como Fator De Risco Para Otite Média Aguda Em Lactentes 66

Avaliação de questionários para mensuração da qualidade de vida relacionada à saúde em pacientes com desordens na deglutição: uma revisão sistemática.

Os impactos da septoplastia para alívio da obstrução nasal.................................................................. 70

Fatores prognósticos em Otite Média Aguda: uma Revisão Sistemática................................................. 72

O impacto do implante coclear na função cognitiva de pacientes idosos com perda auditiva .................. 74

Principais achados da videoendoscopia em pacientes com esclerose amiotrófica .................................... 76

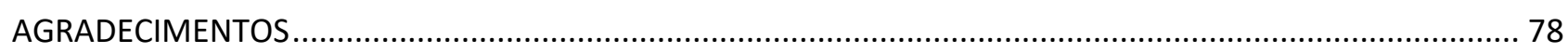




\section{SOBRE O EVENTO}

O I Congresso Online de Otorrinolaringologia Rio-Minas é realizado de forma online na plataforma Doity-Plataforma de gestão e eventos, com iniciativa da Faculdade de Medicina da Universidade Federal de Juiz de Fora, em parceria com outras duas instituições de ensino, através das respectivas ligas acadêmicas de otorrinolaringologia: a Faculdade de Medicina de Petrópolis e a Faculdade de Medicina da Suprema de Juiz de Fora. O congresso realizado no dia 16 de janeiro de 2021, tem previsão de início às 09:20 e término às 17:20, portanto, a duração é de oito horas.

O mote deste evento visa congregar diferentes especialistas, profissionais de saúde e entusiastas pelo conhecimento numa tempestiva conferência, ao passo que, acompanha a realidade mundial da pandemia em uma tendência incipiente de congressos ministrados via plataformas remotas digitais. Abordaremos temas relacionados à pandemia do Covid19 e que se relacionam com a presente especialidade, convidados dos mais variados campos da otorrinolaringologia, que foram selecionados por meio de um plenário entre os especialistas orientadores deste evento, cuja descrição está na organização.

O público alvo do evento são médicos otorrinolaringologistas, fonoaudiólogos, fisioterapeutas, dentistas, pediatras, alergistas, acadêmicos da área da saúde. O público estimado são 2000 pessoas. 


\section{Organizadores do Evento}

\section{Presidência/Diretoria}

Letícia Raquel Baraky Vasconcelos - Médica e doutora em otorrinolaringologia e Presidente do congresso.

João Marcos Faier Assunção - Acadêmico de medicina pela UFJF e gerente do congresso. Ana Silvia Menezes Bastos e Miguel Eduardo Guimarães Macedo - Médicos especialistas em otorrinolaringologia e orientadores do congresso.

\section{Comissão Científica}

Coordenadora científica: Letícia Raquel Baraky Vasconcelos

Integrantes do comitê científico e banca avaliadora:

Fernanda Rodrigues Martins

João Marcos Faier Assunção

Kim da Silva Brum

Lívia Machado Rigolon

Roberta Dezan Feital Filha

\section{Estrutura Administrativa}

Incubência do comitê de infraestrutura do congresso, formado por:

Beatriz Braga Silva

João Marcos Faier Assunção

Manira Helena Basile Lima

Nara de Carvalho Andrade Soares Magaldi 


\section{Programação}

\begin{tabular}{|c|c|c|c|c|}
\hline \multicolumn{5}{|c|}{$16 / 01 / 2021$} \\
\hline Horário & Evento & & & \\
\hline $9: 20$ & Palestra & Obstrução Nasal & $\begin{array}{l}\text { Dr. Miguel Soares } \\
\text { Tepedino }\end{array}$ & Online \\
\hline 10:00 & Palestra & $\begin{array}{l}\text { Insuficiência de } \\
\text { válvula nasal }\end{array}$ & $\begin{array}{l}\text { Dr. Evandro Ribeiro } \\
\text { de Oliveira }\end{array}$ & Online \\
\hline 10:40 & Palestra & Implante coclear & $\begin{array}{l}\text { Dr. Ricardo } \\
\text { Ferreira Bento }\end{array}$ & Online \\
\hline 11:20 & Palestra & $\begin{array}{l}\text { Paralisia Facial } \\
\text { Periférica }\end{array}$ & $\begin{array}{l}\text { Dr. Fernando } \\
\text { Balsalobre }\end{array}$ & Online \\
\hline $11: 40$ & Palestra & $\begin{array}{l}\text { Otoneurologia para o } \\
\text { clínico: } \\
\text { labirintopatias }\end{array}$ & $\begin{array}{l}\text { Dr. Luis Gustavo } \\
\text { Cattai Zamboni }\end{array}$ & Online \\
\hline $12: 40$ & Palestra & $\begin{array}{l}\text { Urgências em } \\
\text { Otorrinolaringologia }\end{array}$ & $\begin{array}{l}\text { Dr. Ricardo } \\
\text { Rodrigues } \\
\text { Figueiredo }\end{array}$ & Online \\
\hline $12: 40-14: 00$ & Break & $\begin{array}{l}\text { Pausa para almoço, } \\
\text { apresentação dos } \\
\text { melhores trabalhos, } \\
\text { sorteios e vídeos }\end{array}$ & Equipe institucional & Online \\
\hline 14:00 & Palestra & Anosmia e Covid-19 & $\begin{array}{l}\text { Dr. Deusdedit } \\
\text { Brandão Neto }\end{array}$ & Online \\
\hline $14: 40$ & Palestra & Otite Média & $\begin{array}{l}\text { Dr. Rodrigo } \\
\text { Guimarães Pereira }\end{array}$ & Online \\
\hline 15:20 & Palestra & Disfonia & $\begin{array}{l}\text { Dr. Bruno Taccola } \\
\text { Niedermeier }\end{array}$ & Online \\
\hline 16:00 & Palestra & Triagem Neonatal & $\begin{array}{l}\text { Fernando César } \\
\text { Rodrigues de Souza }\end{array}$ & Online \\
\hline $16: 40$ & Palestra & SAOS & $\begin{array}{l}\text { Dra. Fernanda } \\
\text { Haddad }\end{array}$ & Online \\
\hline
\end{tabular}




\section{Apresentação}

Os manuscritos são referentes aos trabalhos apresentados no I Congresso de Otorrinolaringologia Rio-Minas, realizado de forma online no dia 16 de janeiro de 2021. A proposta principal desse projeto é difundir o conhecimento em otorrinolaringologia e áreas afins e atualizar profissionais quanto às inovações em tecnologia e pesquisa relacionadas à especialidade. Dessa forma, foram aceitos trabalhos que versassem sobre quaisquer temas relacionados à Otorrinolaringologia, sendo 35 resumos simples no total. Todos os trabalhos foram minuciosamente avaliados por uma comissão científica composta por acadêmicos de medicina e uma médica otorrinolaringologista e doutora em ciências.

Os critérios adotados na seleção dos trabalhos foram:

1) Relevância e Originalidade;

2) Clareza e pertinência dos objetivos;

3) Coerência metodológica;

4) Delineamento da pesquisa adequada aos objetivos;

5) Descrição dos métodos/procedimentos e amostra da pesquisa quando cabível;

6) Descrição clara do tipo de análise utilizada (descritiva ou analítica), adequadas ao delineamento do estudo;

7) Definição clara dos resultados e variáveis do estudo;

8) Importância para o avanço do conhecimento;

9) Potencial de aplicabilidade;

10) Impacto dos resultados.

Aqueles que não preencheram quaisquer critérios foram excluídos. 


\section{RESUMOS SIMPLES}

RESUMO SIMPLES: Revisão Bibliográfica

Título: Aspectos do manejo da Apneia Obstrutiva do Sono em crianças com Síndrome de Down

Autores/coautores: Bruna Campos Souza', Rafael Tonelli Bernardes, Vinícius Pereira de Souza².

Instituição: 'Faculdade de Medicina da Universidade Federal de Minas Gerais (UFMG), Belo Horizonte - MG; ${ }^{2}$ Faculdade de Medicina da Pontifícia Universidade Católica de Minas Gerais (PUC Minas), Betim - MG.

Palavras-chaves: Apneia Obstrutiva do Sono, Síndrome de Down, Crianças.

\section{INTRODUÇÃO}

Apneia Obstrutiva do Sono (AOS) ocorre frequentemente em crianças com Síndrome de Down (SD) entre $45 \%$ a $76 \%$, segundo certas coortes (NERFELDT P e SUNDELIN A, 2020). Isso pode explicar-se por características craniofaciais e comorbidades geralmente associadas à SD (BASSETT EC e MUSSO MF, 2017). Reconhecer AOS através de sintomas clínicos, todavia, tem limitações: relatos de respiração ofegante, ronco ou apneia podem não se associar à AOS - que, ademais, pode cursar sem tais sintomas (SIMPSON $\mathrm{R}$, et al., 2018). Polissonografia (PSG) é exame diagnóstico padrão-ouro, mas é subutilizada nos pacientes elegíveis, com SD (BASSETT EC e MUSSO MF, 2017).

\section{OBJETIVO}

Revisar a literatura científica sobre o manejo atual da AOS em pacientes infantis com SD, destacando as principais evidências, com foco na redução de danos e na melhoria da qualidade de vida.

\section{REVISÃO BIBLIOGRÁFICA}

Como não se pode predizer presença de AOS em crianças com SD pelo quadro clínico, a Academia Americana de Pediatria (AAP) e outras associações recomendam realização rotineira de PSG nesses pacientes, aos 4 anos de idade. Além da maior prevalência comparada à população geral, essas crianças tendem a apresentar AOS mais grave, com risco elevado de desenvolver distúrbios associados (SIMPSON R, et al., 2018).

O tratamento de primeira linha é adenotonsilectomia - conquanto seja menos eficaz em pacientes com SD (BASSETT EC e MUSSO MF, 2017). Frequentemente essa cirurgia não será curativa, observando-se que 50-75\% desses pacientes permanecerão com doença residual significativa pós-adenotonsilectomia. É significativa, entretanto, a redução pós-operatória dos índices de gravidade, segundo parâmetros respiratórios na PSG (SIMPSON R, et al., 2018).

Considerações sobre acesso e anormalidades de vias aéreas, muito prevalentes em SD, são fundamentais à equipe ao planejamento cirúrgico (BASSETT EC e MUSSO MF, 2017). Pressão Positiva Contínua na Via 
Aérea (CPAP) é válida como tratamento adicional pós-adenotonsilectomia - e para pacientes com elevado risco cirúrgico, que requerem procedimento não invasivo (SIMPSON R, et al., 2018).

\section{CONSIDERAÇÕES FINAIS}

A criança portadora de SD requer triagem para AOS a partir dos 4 anos de idade, podendo ser realizada anteriormente, em casos de necessidade. $O$ tratamento da comorbidade deve ser individualizado e a decisão compartilhada com os cuidadores. Pesquisas que estimulem a investigação e o desenvolvimento de terapias adjuvantes têm amplo potencial benéfico a esses pacientes.

\section{REFERÊNCIAS}

1. BASSETT EC, MUSSO MF. Otolaryngologic management of Down syndrome patients: what is new? Current opinion in otolaryngology \& head and neck surgery, 2017; 25(6): 493-497.

2. NERFELDT P, SUNDELIN A. Obstructive sleep apnea in children with Down syndrome - Prevalence and evaluation of surgical treatment. International journal of pediatric otorhinolaryngology, 2020; 133: 109968.

3. SIMPSON R, et al. Obstructive sleep apnea in patients with Down syndrome: current perspectives. Nature and science of sleep, 2018; 10: 287-293. 
RESUMO SIMPLES: Revisão Bibliográfica

Título: Sonolência Excessiva Diurna em Estudantes de Medicina: uma revisão sistemática

Autor/coautores: Rodrigo De Martin Almeida, Aylla Corrêa Gonçalves, Andreza Resende Neiva, Isabella Ribeiro Zago, Miguel Eduardo Guimarães Macedo.

Instituição: Faculdade de Ciências Médicas e da Saúde de Juiz de Fora (FCMS/JF), Juiz de Fora - MG

Palavras-chave: Sonolência excessiva diurna, Transtornos do sono, Estudantes de medicina.

\section{INTRODUÇÃO}

O sono é um comportamento humano essencial na homeostase e sua privação provoca impactos na capacidade laboral e déficit cognitivo. Distúrbios, como apneia obstrutiva do sono, e hábitos modernos de vida alteram o ciclo de sono-vigília, o que pode implicar patologias psíquicas e uso de substâncias (PURIM KSM, et al., 2016). Nessa perspectiva, a Sonolência Diurna Excessiva (SDE) é a incapacidade de manter um nível adequado de vigília e é comum em estudantes de Medicina por sua extensa carga horária e atividades extracurriculares (MACHADO-DUQUEA ME, et al., 2015; GARCIA JAN, et al., 2018).

\section{OBJETIVO}

Revisar a literatura científica dos últimos vinte anos, de modo sistemático, acerca da díade SDE e Estudantes de Medicina, visando compreender a relação e os impactos à saúde desses indivíduos.

\section{MÉTODO}

Realizou-se uma revisão sistemática, em dezembro de 2020, nas bases PubMed e SciELO, por meio dos descritores "Transtornos do Sono" "Sonolência Diurna Excessiva" e "Estudantes de Medicina". Critérios de inclusão: artigos originais dos últimos vinte anos, em língua inglesa, portuguesa e espanhola; critérios de exclusão: não preenchimento da elegibilidade para inclusão. Foram encontrados 22 artigos no total, dos quais selecionaram-se os 3 de maior impacto e relevância.

\section{REVISÃO BIBLIOGRÁFICA}

Uma das principais consequências dos distúrbios do sono é o esgotamento mental, pois a exaustão emocional e a SDE interferem em todo o conjunto biopsicossocial e acadêmico, o que reforça a necessidade de tratamento e acompanhamento profissional. Estudantes de Medicina demonstraram SDE semelhante à dos médicos residentes, confirmando que a pressão emocional começa já na vida acadêmica (PURIM KSM, et al., 2016; MACHADO-DUQUEA ME, et al., 2015).

A prevalência de SDE na população geral varia entre 12 e 16\%, enquanto entre os estudantes de Medicina chega a 49,8\% (MACHADO-DUQUEA ME, et al., 2015). Tais estudantes apresentam piores resultados acadêmicos quando comparados àqueles com boa qualidade de sono ( $p=0,002)$ (GARCIA JAN, et al., 2018). Como tentativa para contornar esse cenário, constata-se consumo excessivo de café e outros estimulantes, além de álcool, que pode exacerbar crises de ansiedade e quadros psíquicos (MACHADO-DUQUEA ME, et al., 2015).

\section{CONSIDERAÇÕES FINAIS}

O curso de Medicina é reconhecido por exigir grande dedicação, entretanto as cargas horária e emocional podem acarretar problemas como a SDE e o esgotamento mental. Assim, faz-se necessário adotar medidas 
que equilibrem a rotina do estudante, priorizando a sua qualidade de vida, de modo a reduzir a ocorrência de sintomas psicopatológicos e uso de substâncias por esta população.

\section{REFERÊNCIAS}

1. GARCÍA JAN, et al. Factores asociados con somnolencia diurna excesiva en estudiantes de Medicina de una institución de educación superior de Bucaramanga. Revista Colombiana de Psiquiatría, 2018; 48(4), 222-231.

2. MACHADO-DUQUEA ME, et al. Somnolencia diurna excesiva, mala calidaddel sueño y bajo rendimiento académicoen estudiantes de Medicina. Revista Colombiana de Psiquiatria, 2015; 44(3), 137-142.

3. PURIM KSM, et al. Privação do sono e sonolência excessiva em médicos residentes e estudantes de medicina. Revista do Colégio Brasileiro de Cirurgiões, 2016; 43(6): 438-444. 
RESUMO SIMPLES: Revisão Bibliográfica

Título: Doença Falciforme e Surdez: Uma revisão sobre a Perda Auditiva Neurossensorial em crianças

Autor/coautores: Rodrigo De Martin Almeida ${ }^{1}$, Nathalia Noyma Sampaio Magalhães ${ }^{1}$, Jordana Alícia Silveira Lopes $^{2}$, Daniela de Oliveira Werneck Rodrigues ${ }^{3}$.

Instituição: ${ }^{1}$ Faculdade de Ciências Médicas e da Saúde de Juiz de Fora (FCMS/JF), Juiz de Fora - MG; 2Universidade Federal de Juiz de Fora (UFJF), Juiz de Fora - MG; ${ }^{3}$ Fundação Hemominas, Juiz de Fora - MG ${ }^{3}$

Palavras-chave: Doença Falciforme, Surdez, Perda auditiva neurossensorial.

\section{INTRODUÇÃO}

A Doença Falciforme (DF) é a patologia hereditária monogênica mais prevalente no mundo. Caracterizase pela presença do gene da hemoglobina $S$ em homozigose, Anemia Falciforme (AF) ou associado a outras hemoglobinopatias (SC, S/beta talassemia e SD Punjab). A AF é a DF de maior gravidade (FARRELL AN, et al., 2019). A surdez na AF decorre de fenômenos vaso-oclusivos que levam à obliteração da artéria labiríntica, resultando em dano isquêmico coclear. A pesquisa da hipoacusia é fundamental para a qualidade de vida dos pacientes falcêmicos (STUART A e SMITH MR, 2019).

\section{OBJETIVO}

Revisar a literatura científica dos últimos cinco anos, de modo sistemático, a respeito da díade Doença Falciforme e perda auditiva em crianças, identificando a prevalência e relacionando à fisiopatologia do processo.

\section{MÉTODO}

Realizou-se revisão sistemática, em dezembro de 2020, nas bases PubMed e SciELO com os descritores "sickle cell disease", "sensorineural hearing loss", e "children". Critérios de inclusão: artigos originais e relatos de caso, entre 2016 e 2020 na língua inglesa; critério de exclusão: não preenchimento da elegibilidade para inclusão. Foram encontrados 10 artigos no total, dos quais selecionaram-se 3 pela sua relevância.

\section{REVISÃO BIBLIOGRÁFICA}

No primeiro estudo, avaliaram-se 128 crianças com DF e verificou-se prevalência de perda auditiva de $28,8 \%$ a $50,8 \%$, com predomínio de condutiva bilateral (29,3\%), seguida por não especificada bilateral $(24,4 \%)$ e neurossensorial bilateral (17,1\%) (STUART A e SMITH MR, 2019). Outra pesquisa, com 72 pacientes, demonstrou que $19,4 \%$ apresentavam perda auditiva, todas unilaterais, $7(9,7 \%)$ condutivas e $6(8,3 \%)$ neurossensoriais (TOWERMAN AS, et al., 2019). Um terceiro trabalho encontrou prevalência menor (13,3\%), predominando a perda neurossensorial (FARRELL AN, et al., 2019).

A média de tom puro de três frequências encontrada por Stuart e Smith foi 30,7 e 29,1 dB de níveis de ruído em orelhas direita e esquerda, respectivamente, enquanto Farrell et al. identificaram média de 43,3 e 40,8 dB. A idade média de realização do primeiro audiograma, para os três estudos, foi 8,3 anos (STUART A e SMITH MR, 2019; TOWERMAN AS, et al., 2019; FARRELL AN, et al., 2019).

\section{CONSIDERAÇÕES FINAIS}

A prevalência de perda auditiva em crianças com DF é maior que na população infantil em geral. A avaliação da audição deve ser periódica e novos estudos são necessários para correlacionar surdez e DF. 
Há necessidade de diagnóstico precoce e acompanhamento das crianças com DF, visto que a perda auditiva acarreta danos ao desenvolvimento cognitivo e biopsicossocial.

\section{REFERÊNCIAS}

1. FARRELL AN, et al. Sensorineural hearing loss in children with sickle cell disease. International Journal of Pediatric Otorhinolaryngology, 2019; 118: 110-114.

2. STUART A, SMITH MR. The emergence and prevalence of hearing loss in children with homozygous sickle cell disease. International Journal of Pediatric Otorhinolaryngology, 2019. 123: 69-74.

3. TOWERMAN AS, et al. Prevalence and nature of hearing loss in a cohort of children with sickle cell disease. Pediatric Blood \& Cancer, 2019; 66(1): e27457. 
RESUMO SIMPLES: Revisão Bibliográfica

Título: Tratamento da Otite Média Aguda por antibioticoterapia em crianças menores de três anos

Autor/coautores: Andreza Resende Neiva, Isabella Ribeiro Zago, Rodrigo De Martin Almeida, Aylla Corrêa Gonçalves, Miguel Eduardo Guimarães Macedo.

Instituição: Faculdade de Ciências Médicas e da Saúde de Juiz de Fora (FCMS/JF), Juiz de Fora - MG.

Palavras-chave: Otite média aguda, Tratamento, Crianças.

\section{INTRODUÇÃO}

A otite média aguda (OMA) é uma condição dolorosa comum em crianças de principalmente três anos de idade, que apresenta impactos à saúde infantil se não for tratada nos casos complicados e se for recorrente, possuindo como principais sintomas febre, irritabilidade e problemas relacionados com alimentação e sono (HAY AD, et al., 2019). Embora a OMA desapareça sem tratamento em $80 \%$ dos casos, pode ser necessária a prescrição antibiótica, mas é importante evitar o uso irracional desses medicamentos devido aos efeitos adversos e resistência antimicrobiana (VENEKAMP RP, et al., 2015).

\section{OBJETIVO}

Revisar os quadros de OMA em crianças de até três anos de idade com o tratamento por antibióticos, apresentando pontos positivos e negativos e a necessidade da indicação dessa terapêutica.

\section{MÉTODO}

Realizou-se uma revisão sistemática nas bases PubMed e SciELO, em dezembro de 2020, utilizando os descritores "Acute Otitis Media", "Treatment" e "Children". Foram incluídos estudos de língua inglesa, ensaio clínico controlado, crianças de zero a 36 meses de idade e nos últimos cinco anos e excluídos aqueles que não abordassem o tema. De 9 artigos encontrados, três de maior relevância foram escolhidos.

\section{REVISÃO BIBLIOGRÁFICA}

Os resultados das pesquisas indicam que $60 \%$ das crianças têm um ou mais episódios de OMA até os três anos de idade e, assim, esta é a causa mais frequente de prescrição antibiótica na pediatria. Após o diagnóstico de OMA deve-se observar de 48 a 72 horas os sintomáticos, podendo prescrever lbuprofeno para analgesia, e realizar a reavaliação do paciente com otoscopia devido a maioria das otites apresentarem resolução espontânea por serem de etiologia viral (VENEKAMP RP, et al., 2015).

Essa conduta é importante para reduzir o uso exagerado de antibióticos, pois a antibioticoterapia deve ser recomendada quando houver OMA complicada, nos quadros de otalgia intensa com otorréia, sendo bilateral e encontrada em pacientes menores de dois anos, visto que essa terapêutica produz uma pequena redução da dor em dois a três dias desde a avaliação inicial (HAY AD, et al., 2019). Dentre os efeitos colaterais, o uso indiscriminado dos antibióticos pode causar diarreia, vômitos e erupção cutânea, além de aumentar a resistência antimicrobiana (BRASIL, 2016).

\section{CONSIDERAÇÕES FINAIS}

A prescrição de antibióticos no tratamento da OMA é a mais prevalente, mas é importante diferenciar e avaliar para qual caso clínico da criança essa terapêutica será útil, já que o uso indiscriminado da antibioticoterapia pode cursar com consequências negativas, como a resistência. 


\section{REFERÊNCIAS}

1. BRASIL, Sociedade de Pediatria de São Paulo. 2016. Disponível em: https://www.spsp.org.br/site/asp/boletins/AT3.pdf. Acessado em: 01 de dezembro de 2020.

2. HAY AD, et al. Anaesthetic-analgesic ear drops to reduce antibiotic consumption in children with acute otitis media: the CEDAR RCT. Health Technol Assess, 2019; 23(34): 1-48.

3. VENEKAMP RP, et al. Antibiotics for acute otitis media in children. Cochrane Library, 2015; 6: 1-71. 
RESUMO SIMPLES: Revisão Bibliográfica

Título: Disfonia Ocupacional em Professores e Sintomatologia Associada

Autor/Coautores: Aylla Corrêa Gonçalves, Andreza Resende Neiva, Isabella Ribeiro Zago, Rodrigo De Martin Almeida, Miguel Eduardo Guimarães Macedo.

Instituição: Faculdade de Ciências Médicas e da Saúde de Juiz de Fora (FCMS/JF - SUPREMA), Juiz de Fora - MG.

Palavras-chave: Disfonia ocupacional, Professor, Distúrbio da voz.

\section{INTRODUÇÃO}

A disfonia é definida como dificuldade na produção da voz que restringe a produção natural da voz e acarreta uma alteração na comunicação oral efetiva. Os professores são um grupo de alto risco para essa condição e apresentam elevada frequência de sintomas vocais referidos (MEDEIROS JSA, et al., 2016; CAVALCANTI NR, et al., 2018). Alguns fatores físicos e ambientais são agravantes no processo de adoecimento e afastamento do docente como a jornada de trabalho prolongada, demanda vocal excessiva por barulhos externos, ausência de pausas e dificuldade de acesso à hidratação (VALENTE AMSL, et al., 2015).

\section{OBJETIVO}

Analisar, por meio de uma revisão sistemática, a sintomatologia associada ao quadro de disfonia ocupacional em docentes, a fim de compreender a dimensão, a importância e a seriedade dessa patologia.

\section{MÉTODO}

Realizou-se uma pesquisa sistemática nas bases de dados MedLine e SciELO, em Dezembro de 2020, por meio dos descritores "Occupational Dysphonia", "Teacher" e "Voice Disorder" e suas variações. Foram incluídos artigos originais, redigidos nas línguas inglesa e portuguesa dos últimos vinte anos e excluídos artigos que não abordassem diretamente o tema. Dos 13 artigos selecionados, três foram de maior relevância.

\section{REVISÃO BIBLIOGRÁFICA}

O estudo que analisou 103 prontuários de docentes do sexo feminino, os sintomas vocais mais presentes foram fadiga da voz após uso excessivo (64,4\%), garganta seca $(50 \%)$ e pigarro $(37,5 \%)$. Variáveis como a presença de poeira em sala, ruídos externos à escola e conversas paralelas na sala de aula foram relatados por aquelas que notaram acima de três sintomas vocais (56,7\%) (MEDEIROS JSA, et al., 2016).

Outro estudo analisou 317 professores de ambos os sexos, $81 \%$ relataram distúrbio de voz (DV), sendo que $57,7 \%$ apontam como possível causa o seu uso intenso. Os sintomas mais prevalentes foram rouquidão (72,3\%), garganta seca $(74,6 \%)$, esforço ao falar $(64,5 \%)$ e cansaço ao falar $(60,6 \%)$. As variáveis associadas ao DV foram as presenças de estresse no trabalho e de poeira no local de trabalho, como o pó de giz (VALENTE AMSL, et al., 2015).

\section{CONSIDERAÇÕES FINAIS}

Professores são alvos de alterações na voz, enquadrando-se na categoria de pacientes com disfonia ocupacional. A alta prevalência de DV entre os docentes demonstra que aspectos relacionados ao ambiente, presença de estresse, poeira no local de trabalho, são os principais fatores associados ao DV. Sendo assim, 
faz-se necessário a orientação de medidas preventivas para reduzir essas porcentagens e melhorar a qualidade da voz e de vida dos docentes.

\section{REFERÊNCIAS}

1. CAVALCANTI NR, et al. Efeito do programa integral de reabilitação vocal em professoras com disfonia comportamental. Communication Disorders, Audiology and Swallowing,2018; 30(4): e20170182.

2. MEDEIROS JSA, et al. Sintomas vocais relatados por professoras com disfonia e fatores associados. Audiology - Communication Research, 2016; 21: e1553.

3. VALENTE AMSL, et al. Distúrbio de voz e fatores associados em professores da rede pública. Revista Brasileira de Saúde Ocupacional, 2015; 40(132):183-95. 
RESUMO SIMPLES: Revisão Bibliográfica

Título: Angiofibroma nasal juvenil: características tumorais e tratamento

Autor/Coautores: Isabella Ribeiro Zago, Rodrigo De Martin Almeida, Aylla Corrêa Gonçalves, Andreza Resende Neiva, Miguel Eduardo Guimarães Macedo.

Instituição: Faculdade de Ciências Médicas e da Saúde de Juiz de Fora (FCMS/JF - SUPREMA), Juiz de Fora - MG.

Palavras-chave: Angiofibroma nasal juvenil, Neoplasia, Tratamento cirúrgico.

\section{INTRODUÇÃO}

O angiofibroma nasal juvenil (ANJ) é um tumor benigno que apresenta grande capacidade de erosão óssea e de invasão de cavidades adjacentes. Acomete principalmente adolescentes do sexo masculino e é responsável por $0,05 \%$ dos tumores de cabeça e pescoço (GOŁĄBEK W, et al., 2019). Sua ressecção pode apresentar maior complexidade devido ao aumento do risco de hemorragias intraoperatórias (CÁRDENAS $A D, 2018$ ). A literatura apresenta técnicas cirúrgicas que possibilitam o tratamento do $A N J$, dentre as quais buscam-se as menos invasivas e capazes de reduzir os riscos de recidiva tumoral (RUBIO-ESPINOZA A, et al., 2018).

\section{OBJETIVO}

Investigar, por meio de uma revisão da literatura científica dos últimos cinco anos, as características anatomohistopatológicas do ANJ, assim como as técnicas cirúrgicas mais utilizadas para o tratamento deste tumor.

\section{MÉTODO}

Foi realizada uma revisão sistemática nas bases de dados MedLine e SciELO em dezembro de 2020 por meio dos descritores: "Juvenile Nasopharyngeal Angiofibroma" e "Treatment" e suas variações. Foram incluídos artigos originais dos últimos cinco anos, em língua inglesa e espanhola e excluídos artigos que não abordassem diretamente o tema. De um total de 66 artigos, foram escolhidos três de maior relevância.

\section{REVISÃO BIBLIOGRÁFICA}

Anatomicamente, o ANJ localiza-se na região superior da nasofaringe, com possibilidade de expansão para estruturas vizinhas, como os seios paranasais ou o assoalho do crânio. Já histologicamente, caracterizase como uma massa de tecido fibroso altamente vascularizado, no entanto, a camada muscular lisa está ausente em seus vasos (CÁRDENAS AD, 2018).

A escolha da técnica cirúrgica para o tratamento destes tumores está relacionada ao estadiamento do ANJ, que pode ser feito através de sistemas, considerando o grau de crescimento e expansão tumoral, sendo os mais utilizados os de Fisch, Andrews e Radkowski (GOŁĄBEK W, et al., 2019). Dentre as cirurgias com abordagens abertas, as três principais técnicas podem ser classificadas em acessos transfaciais, transpalatinos e sublabial. Há ainda a possibilidade de ressecção endoscópica, a qual apresenta vantagens por se tratar de um método menos invasivo, porém não pode ser aplicada para o tratamento de todos os estágios de ANJ, devido a suas limitações quando há o comprometimento de áreas de risco (CÁRDENAS $A D, 2018)$.

\section{CONSIDERAÇÕES FINAIS}


Apesar da benignidade do ANJ, as características deste tumor representam uma dificuldade para seu manejo cirúrgico. Além disso, cada vez mais, buscam-se tratamentos capazes de realizar a ressecção completa do tumor, reduzindo o risco de recidiva, e que ainda proporcionem o melhor prognóstico ao paciente.

\section{REFERÊNCIAS}

1. CÁRDENAS AD. Estado actual del tratamiento del angiofibroma nasal juvenil. Rev Med Hered, 2018; 29(1): 52-57.

2. GOŁABEK W, et al. Juvenile nasopharyngeal angiofibroma with intracranial extension - diagnosis and treatment. Otolaryngol Pol, 2019; 74(2): 1-7.

3. RUBIO-ESPINOZA A, et al. Experiencia en el tratamiento quirúrgico del angiofibroma nasal juvenil en Hospital de Especialidades No 2 Lic. Luis Donaldo Colosio Murrieta. Instituto Mexicano del Seguro Social de Ciudad Obregón, Sonora. Horiz Med, 2018; 18(3): 71-79. 
RESUMO SIMPLES: Revisão Bibliográfica

Título: Tratamento da Síndrome da Apneia Obstrutiva do Sono através de cirurgia ortognática

Autor/coautores: Isabella Soares de Freitas, Ana Carolina Alves Meneses, Márcio Rabelo Mota.

Instituição: Centro Universitário de Brasília (UniCeub), Brasília - DF.

Palavras-chave: Apneia do sono tipo obstrutiva, Cirurgia ortognática, Resultado do procedimento.

\section{INTRODUÇÃO}

A Síndrome da Apneia Obstrutiva do Sono (SAOS) é uma condição causada pelo estreitamento ou colapso das vias aéreas superiores (VAS) durante o sono, sendo um distúrbio cada vez mais diagnosticado. Ela causa diversos sintomas que acometem a qualidade de vida do indivíduo, como sensação de sufocamento ao despertara, por isso, é importante ser feita uma avaliação acerca do melhor tratamento, já que alguns apresentaram limitações [a] (ASSIS MR, et al., 2019). A cirurgia ortognática (CO) tem sido escolhida nos últimos anos por se mostrar uma intervenção eficaz nos casos moderados e graves da SAOS, já que ajuda nas obstruções das VAS durante o sono.

\section{OBJETIVO}

Revisar a literatura científica acerca da eficácia da cirurgia ortognática como tratamento da SAOS, pontuando como ocorre a correção cirúrgica e os principais resultados e benefícios decorrentes desse procedimento na qualidade de vida do paciente.

\section{REVISÃO BIBLIOGRÁFICA}

A SAOS é causada por alterações da anatomia craniofacial que geram estreitamento das VAS, resultando em piora da qualidade de vida. Entre os diversos disponíveis, a cirurgia ortognática tem se tornado um tratamento promissor para a melhora do potencial de vida destes pacientes ${ }^{a}$ [a] (ASSIS MR, et al., 2019).

A CO gera aumento do diâmetro do espaço nasofaríngeo e bucofaríngeo através de avanços mandibulares, maxilares ou bi-maxilares, objetivando eliminar os defeitos anatômicos que causem a oclusão das VAS. A movimentação da mandíbula para frente aumenta a via aérea hipofaríngea, já a da maxila e palato aumentam a da região retropalatal, diminuindo a probabilidade de colapso das VAS ${ }^{b}$ [b] (PANISSA, C, et al., 2018).

O procedimento se mostra eficaz já no pós-operatório imediato, gerando melhora progressiva de alguns sintomas, como o ronco. A longo prazo, evidencia-se diminuição ou eliminação da apneiac [c] (FEITOZA, CHRISTIANE, et al., 2017). Além disso, apresenta baixo índice de insatisfação, diferente do uso do CPAP, por exemplo, e dá a possibilidade de gerar mudanças positivas na estética do paciente.

\section{CONSIDERAÇÕES FINAIS}

A partir da análise dos dados, conclui-se que a $\mathrm{CO}$ se apresenta como um método promissor e eficaz no tratamento da síndrome, já que gera altos índices de diminuição e eliminação dos sintomas, havendo melhora na qualidade de vida do indivíduo, se mostrando, então, uma opção bem-sucedida.

\section{REFERÊNCIAS}


1. ASSIS MR, et al. O papel da cirurgia ortognática no tratamento da síndrome de apnéia obstrutiva do sono. Archives of health investigation, 2018; 7: e3910

2. FEITOZA, CHRISTIANE, et al. Cirurgia ortognática no tratamento da síndrome da apneia obstrutiva do sono - relato de caso. Editora Plena, 2017; 10 (38): 98-105.

3. PANISSA, C, et al. Cirurgia ortognática para tratamento da síndrome de apneia obstrutiva do sono: relato de caso. Revista da Faculdade de Odontologia, 2018; 22: 337-341. 
RESUMO SIMPLES: Revisão Bibliográfica

Título: Correlação entre Rinite, Gestação e o Período Pós-Parto

Autor/coautores: Júlia Abrahão Lopes, Alice Filgueiras Netto, Aline Batista Brighenti dos Santos, Miguel Eduardo Guimarães Macedo.

Instituição: Faculdade de Ciências Médicas e da Saúde de Juiz de Fora (FCMS/JF), Juiz de Fora - MG.

Palavras-chave: Gestação, Obstrução nasal, Rinite.

\section{INTRODUÇÃO}

A gravidez pode levar a alterações no trato respiratório pois nele existem receptores de hormônios que estão alterados nessa fase. Essas modificações respiratórias podem se caracterizar como rinite durante a gestação, piora de sintomas pré-existentes, ou Rinite Gestacional (RG) (BAUDOIN T, et al., 2020). A RG é definida como obstrução nasal não presente antes da gestação, com aparecimento dos sintomas no segundo ou terceiro trimestre, duração mínima de seis semanas, sem sintomas alérgicos ou de infecções do trato respiratório e que desaparece com duas semanas pós-parto (CAPARROZ FA, et al., 2016).

\section{OBJETIVO}

Investigar a correlação existente entre os sintomas de obstrução nasal, o período gestacional e a duração da sintomatologia no puerpério, considerando rinite não alérgica do tipo hormonal, especificamente a RG.

\section{MÉTODO}

Realizou-se uma revisão sistemática na base PubMed e em revistas científicas internacionais, em dezembro de 2020, utilizando os descritores: "Rhinitis", "Pregnancy", "Nasal Obstruction". Foram incluídos artigos publicados nos últimos cinco anos, em língua inglesa e diretamente relacionados ao tema e excluídos artigos que utilizaram qualquer tipo de intervenção. Foram encontrados nove artigos, selecionando cinco de maior relevância.

\section{REVISÃO BIBLIOGRÁFICA}

Um estudo longitudinal revelou que em mais de $50 \%$ das entrevistadas os sintomas de rinite agravaram na gravidez. O diagnóstico de RG ocorreu em $30 \%$ dos casos, iniciando no final do segundo semestre $(p<0,001)$ e 53,5\% involuiu até o $15^{\circ}$ dia pós-parto. O sintoma principal foi congestão nasal: 98,2\% (BAUDOIN T, et al., 2020).

O hormônio trofoblástico placentário estimula a hipertrofia da mucosa nasal. O estrogênio aumenta os receptores de histamina nas células epiteliais e endoteliais microvasculares, diminuindo a permeabilidade das fossas nasais, eleva o componente do ácido hialurônico e inibe a acetilcolinesterase causando edema de mucosa. A progesterona aumenta a vasodilatação nasal. Esses mecanismos geram os sintomas mais comuns, obstrução nasal e rinorréia (CAPARROZ FA, et al., 2016; LOSS TB, et al., 2017; MULLOL J, et al., 2020).

O estrogênio provoca congestão nasal e hipersecreção, o beta-estradiol e a progesterona induzem a migração de eosinófilos por aumentar os receptores histaminérgicos no epitélio nasal e no endotélio microvascular (HELLINGS PW, et al., 2017).

\section{CONSIDERAÇÕES FINAIS}


A partir dos resultados apresentados, a correlação entre obstrução nasal, o seu início entre segundo e terceiro trimestres de gravidez e o fim dos sintomas no período de até 15 dias pós-parto, é hormonal, relacionada principalmente ao estrogênio e à progesterona e é definida como RG.

\section{REFERÊNCIAS}

1. BAUDOIN T, et al. Redefining Pregnancy-Induced Rhinitis. Am J Rhinol Allergy, 2020; 0: 1-8.

2. CAPARROZ FA, et al. Rhinitis and pregnancy: literature review. Braz J Otorhinolaryngol, 2016; 82: 10511.

3. HELLINGS PW, et al. Non-allergic rhinitis: Position paper of the European Academy of Allergy and Clinical Immunology. Allergy, 2017; 72: 1657-65.

4. LOSS TB, et al. Gestational Rhinitis. J Multidiscip Res. Special Edition of Health. Year 02 2017; 04: 11422.

5. MULLOL J, et al. Rhinitis Phenotypes. J Allergy Clin Immunol Pract, 2020; 8: 1492-503. 
RESUMO SIMPLES: Revisão Bibliográfica

Título: Eficácia da Manobra de Epley no Tratamento da Vertigem Posicional Paroxística Benigna

Autor/coautores: Alice Filgueiras Netto, Miguel Eduardo Guimarães Macedo, Aline Batista Brighenti Santos, Júlia Abrahão Lopes.

Instituição: Faculdade de Ciências Médicas e da Saúde de Juiz de Fora (FCMS/JF), Juiz de Fora - MG.

Palavras-chave: Manobra de Epley, Tratamento, Vertigem Posicional Paroxística Benigna.

\section{INTRODUÇÃO}

A Vertigem Posicional Paroxística Benigna (VPPB) é caracterizada por breves episódios de vertigem acompanhada de nistagmo. Seus sintomas são provocados pela mudança na posição da cabeça/pescoço, que desencadeiam o deslocamento de detritos otocônicos (cristais de carbonato de cálcio) do utrículo para o canal semicircular (SABERI A, et al., 2017).

O tratamento indicado para a VPPB inclui manobras de reposicionamento canalicular, como a de Epley, que utiliza de movimentos e posições para deslocar os fragmentos em torno do canal semicircular e trazer de volta ao utrículo, aliviando os sintomas(SABERI A, et al., 2017; LIU Y, et al., 2016).

\section{OBJETIVO}

Revisar a literatura científica sobre a eficiência do uso da Manobra de Epley no tratamento de pacientes diagnosticados com VPPB considerando uma melhora em sua qualidade de vida e bem-estar.

\section{MÉTODO}

Realizou-se revisão sistemática na base PubMed, com os descritores "Benign Paroxysmal Positional Vertigo"; "Epley Maneuver"; "Treatment". Foram incluídos estudos de evidência A, publicados nos últimos cinco anos, na língua inglesa e realizados em humanos, excluindo aqueles que não cumpriram parâmetros de inclusão. Foram encontrados oito artigos, selecionando os quatro de maior relevância.

\section{REVISÃO BIBLIOGRÁFICA}

Uma meta-análise revisou 12 artigos, com um total de 999 pacientes, sendo que 11 estudos demonstraram uma eficácia de 70\% a $96 \%$ do uso de Epley no tratamento da VPPB. Resultados promissores foram apresentados tanto após uma semana quanto ao final dos testes (seis meses), sendo que, em cinco artigos, Epley foi considerado duas vezes mais eficaz que outras manobras no tratamento a longo prazo (LIU Y, et al., 2016).

Em dois ensaios clínicos, um com 30 pacientes submetidos a Epley em três posições e outro com 25 pacientes, houve uma melhora na qualidade de vida e nos sintomas dos participantes que passaram pela manobra de reposição canalicular $-60 \%$ em um dia no primeiro estudo-, com baixa frequência de complicações (SABERI A, et al., 2017, UZ U, et al., 2019).

Em outro artigo, 108 pacientes sofreram intervenção com Epley, sendo que 79\% obtiveram uma melhora de seus sintomas após 24 horas do procedimento, e, em 48 horas, essa taxa subiu para 94\% (SONG MH, et al., 2020).

\section{CONSIDERAÇÕES FINAIS}


A manobra de Epley se mostrou eficaz no tratamento da VPPB pois é um procedimento não invasivo e de fácil gerenciamento, proporcionando um alívio rápido e eficiente dos sintomas. Ademais, apresentam baixo índice de efeitos colaterais, melhorando a qualidade de vida dos pacientes.

\section{REFERÊNCIAS}

1. LIU Y, et al. Epley and Semont maneuvers for posterior canal benign paroxysmal positional vertigo: A network meta-analysis. Laryngoscope, 2016; 126(4): 951-955.

2. SABERI A, et al. A safe-repositioning maneuver for the management of benign paroxysmal positional vertigo: Gans vs. Epley maneuver; a randomized comparative clinical trial. Eur Arch Otorhinolaryngol, 2017; 274(8): 2973-2979.

3. SONG MH, et al. Optimal reassessment time for treatment response in posterior canal benign paroxysmal positional vertigo. Laryngoscope, $2020 \mathrm{Feb}$; 130(2): 496-499.

4. UZ U, et al. Efficacy of Epley Maneuver on Quality of Life of Elderly Patients with Subjective BPPV. J IntAdvOtol, 2019; 15(3): 420-424. 
RESUMO SIMPLES: Revisão Bibliográfica

Título: Tratamento Cirúrgico versus Tratamento Conservador em Leucoplasia de Pregas Vocais

Autor/coautores: Rebecca Maria Campos Diniz, Miguel Eduardo Guimarães Macedo, Beatriz Soares Montandon, Júlia Melo Pereira, Amanda Mendes Lourenço.

Instituição: Faculdade de Ciências Médicas e da Saúde de Juiz de Fora (FCMS/JF), Juiz de Fora - MG.

Palavras-chave: Leucoplasia, Pregas vocais, Tratamento.

\section{INTRODUÇÃO}

Embora existam várias definições, esse artigo abordará o conceito de leucoplasia de pregas vocais (LPV) como uma lesão benigna pré-neoplásica, de acordo com a Organização Mundial da Saúde (OMS), diagnosticada clinicamente por meio de lesões brancas intraepiteliais escamosas, hipertrofia epitelial anormal ou displasia das pregas vocais (Li C, et al., 2018). Ademais, pode ocorrer uma progressão maligna, sendo caracterizada, geralmente, como displasia severa ou carcinoma in situ. Com a existência de métodos cirúrgicos e conservadores para o tratamento, torna-se necessário a busca pela opção mais adequada (LI C, et al., 2018; GAO X-W, et al., 2015).

\section{OBJETIVO}

Classificar e investigar os estágios de LPV e, a partir disso, comparar o desempenho e a performance de ambos os tipos terapêuticos, sendo eles os tratamentos cirúrgicos e o conservador.

\section{MÉTODO}

Realizou-se revisão sistemática na base National Library of Medicine (MEDLINE), em dezembro/2020, com os descritores: leucoplasia, pregas vocais e tratamento, e suas variações obtidas no Medical SubjectHeadings (MeSH). Critério de inclusão: ensaios clínicos publicados nos últimos cinco anos, em língua inglesa, comparando os tratamentos cirúrgico e conservador, excluindo os demais. Dos quatro artigos encontrados, apenas um foi utilizado e, através da busca continuada, outros três foram selecionados, totalizando quatro artigos.

\section{REVISÃO BIBLIOGRÁFICA}

Os estudos revelaram classificações da LPV de leve (LPVL) a severa (LPVS). A LPVL, apresenta textura lisa, com coloração homogênea. Já a LPVS, tem textura irregular, com diferentes colorações, acompanhada por ulcerações. Fatores como tabagismo, refluxo e alcoolismo são considerados grandes precursores para a progressão do quadro (CHEN M, et al., 2017).

Um estudo analisou 24 pacientes com diagnóstico de LPV. Após seis meses com tratamento conservador (20mg de rabeprazol), sete pacientes mostraram uma resposta completa, caracterizando a LPVL; 12 apresentaram uma resposta parcial; e cinco não responderam ao tratamento, caracterizando a LPVS. Essa menor parcela foi encaminhada para cirurgia (GOKTAS SSG, et al., 2019).

Outro estudo envolvendo 178 pacientes com LPV, abordou o tratamento conservador (20mg de omeprazol duas vezes ao dia e ausência do consumo de álcool e cigarro). Após seis meses, indivíduos com LPVL apresentaram uma melhora total, enquanto indivíduos com LPVS foram encaminhados ao tratamento cirúrgico (CHEN M, et al., 2017).

\section{CONSIDERAÇÕES FINAIS}


A classificação de LPV é de extrema importância para a decisão do método terapêutico. Com isso, o tratamento conservador pode ser uma alternativa eficaz e menos arriscada para pacientes com LPVL. Já no contexto de LPVS, o tratamento cirúrgico mostrou-se mais indicado.

\section{REFERÊNCIAS}

1. CHEN M, et al. Nonsurgical Treatment for Vocal Fold Leukoplakia: An Analysis of 178 Cases. BioMed Research International 2017; 2017: 1-7.

2. GAO X-W, et al. Use Videostrobokymography to Quantitatively Analyze the Vibratory Characteristics Before and After Conservative Medical Treatment of Vocal Fold Leukoplakia. Journal of Voice 2015; 30(2): 215-20.

3. GOKTAS SSG, et al. A new approach to vocal cord leukoplakia and evaluation of proton pump inhibitor treatment. European Archives of Oto-Rhino-Laryngology 2019; 276(2): 467-471.

4. LIC, et al. A new classification of vocal fold leukoplakia by morphological appearance guiding the treatment. Acta Oto-Laryngologica 2018; 138(6): 584-589. 
RESUMO SIMPLES: Revisão Bibliográfica

Título: Associação entre infecção pelo HPV e o câncer de cavidade oral e orofaringe

Autor/coautores: Lucas Sabbagh Loures Vieira, Miguel Eduardo Guimarães Macedo, Layla Vital Bressan, Naimara de Oliveira Frizzero, William Gomes Rosa.

Instituição: Faculdade de Medicina da Faculdade de Ciências Médicas e da Saúde de Juiz de Fora (FCMS/JF), Juiz de Fora - MG.

Palavras-chave: Carcinoma, Papilomavírus, Orofaringe.

\section{INTRODUÇÃO}

O câncer de orofaringe é o quarto tumor mais frequente no sexo masculino na região Sudeste de acordo com o INCA (Instituto Nacional de Câncer, 2020). O carcinoma de células escamosas de orofaringe (CCEO) está cada vez mais associado ao Papilomavírus Humano (Human Papiloma Virus - HPV), visto que o elitismo e o tabagismo têm sido menos frequentes atualmente (WITTEKINDT C, et.al., 2018). Recentemente, novos estudos identificam a presença de DNA viral associado ao CCEO, porém as técnicas de análise de presença do material viral e a relação com o HPV e seus subtipos ainda não é linear (WOOD ZC, et al., 2017).

\section{OBJETIVO}

Analisar a existência ou não de correlação direta ou indireta entre a presença do DNA viral do HPV e seus subtipos com o desenvolvimento do CCEO e sua possível evolução.

\section{MÉTODO}

Essa revisão integrativa foi feita na base de pesquisa MEDLINEcom busca adicional de informações clínico-epidemiológicas na base de dados SciELO. Selecionou-se estudos dos últimos 5 anos de revisão de literatura e meta-análise com a frase de pesquisa (oropharyngeal[MeSHTerms] OR "tongue cancer" OR "oral cavity") AND (HPV) que correlacionava o CCEO com o vírus HPV. Foram encontrados 379 estudos relevantes, dentre os quais destacou-se alguns ratificando a relação e outros negando-a.

\section{REVISÃO BIBLIOGRÁFICA}

O câncer de cavidade oral é uma doença de etiologia complexa o qual sofre influência genética e comportamental. Há fortes evidências de que o HPV possa estar envolvido no câncer de orofaringe (BRASIL,2017). Em uma meta-análise que envolveu 14 estudos, demonstrou-se que o CCEO está intimamente relacionado ao HPV (RAPADO-GONZÁLEZ Ó, et al., 2020), todavia na mesma proporção ele também não é encontrado e não pode ser classificado como causa desses tumores, verificado em 171 pacientes (ABREU PM de, et al., 2018).

A etiopatogenia ainda não é clara, referindo-se principalmente a evidências conflitantes na detecção de tais vírus no carcinoma oral. Estudos sugerem que a metodologia e a testagem, além de sua especificidade para os diferentes subtipos, mascaram os resultados (WOOD ZC, et al., 2017). É necessário que novos estudos sejam feitos com uma padronização de testagem, a fim de que o HPV seja, de fato, preditivo no desenvolvimento dos CCEO.

\section{CONSIDERAÇÕES FINAIS}


Não há consenso na relação entre HPV e o CCEO, oncogenicidade e pior prognóstico. Técnicas que envolvem o rastreamento de todas as variantes, além do HPV-16, como imunohistoquímica e real-time PCR podem esclarecer essas questões. Além disso, deve ser feita uma distinção da oncogênese bucal da cervical.

\section{REFERÊNCIAS:}

1. ABREU PM DE, et al. Frequencyof HPV in oral cavitysquamouscell carcinoma. BMC Cancer. 2018; 18(324): 1-8: PMID: 29580212.

2. BRASIL. Instituto Nacional de Câncer. 2020. Disponível em: https://www.inca.gov.br/tipos-decancer/cancer-de-boca. Acessado em: 01 de dezembro de 2020.

3. BRASIL. Sociedade Brasileira de Oncologia Clínica. 2017. Disponível em: https://sboc.org.br/images/diretrizes/diretrizes_pdfs/Cabe\%C3\%A7a_e_pescoco_vf_2017.pdf. Acessado em: 05 de dezembro de 2020.

4. RAPADO-GONZÁLEZ Ó, et al. Association of Salivary Human Papillomavirus Infection and Oral and Oropharyngeal Cancer: A Meta-Analysis.Journal of Clinical Medicine. 2020; 9(5): p.1-18: PMID: 32370055.

5. WITTEKINDT C, et al. HPV - A different view on Head and Neck Cancer. Laryngorhinootologie. 2018; 97(1): 548-81: PMID: 29905354.

6. WOOD ZC, et al. Oral human papillomavirus infection incidence and clearance: a systematic review of the literature. Journalof General Virology. 2017; 98(4): 519-26: PMID: 28150575. 
RESUMO SIMPLES: Revisão Bibliográfica

Título: Disfunção Olfatória e Gustativa na Covid-19

Autor/coautores: Bernardo Valle Zanetti, Daniel Camargo de Andrade, Mauricio Silva de Moraes Souza, Milla Giancristofaro Dutra, Miguel Eduardo Guimarães Macedo.

Instituição: Faculdade de Medicina da Faculdade de Ciências Médicas e da Saúde de Juiz de Fora (FCMS/JF), Juiz de Fora - MG.

Palavras-chave: Infecção coronavírus, Disfunção olfatória, Disfunção gustativa.

\section{INTRODUÇÃO}

A pandemia causada pelo vírus SARS-CoV-2 é um dos principais focos de estudos em 2020 e, pode-se relacionar a presença de Disfunções Olfatórias e Gustativas (DOG) com o contágio moderado da Covid-19, considerando-os como marcadores de intensidade (COSTA KVTD, et al., 2020). Desse modo, esses sintomas são indicadores, mesmo sem prévio diagnóstico por RT-PCR (Real-Time Reverse-TranscriptionPolymerase Chain Reaction) (AGYEMAN AA, et al., 2020; COSTA KVTD, et al., 2020; HOANG MP, et al., 2020; TONG JY, et al., 2020), de forma que sua análise é fundamental para o combate e controle da pandemia.

\section{OBJETIVO}

Investigar o possível estado da arte sobre a relação dos sintomas de Disfunção Olfatória e Gustativa, bem como o grau de complicação causado pela infecção nos casos do novo Coronavírus (Covid-19).

\section{MÉTODO}

Durante o mês de dezembro de 2020, foi realizada uma revisão sistemática na base de dados MedLine, utilizando os descritores: "CoronavirusInfections"; "GustatoryDysfunction"; "OlfactionDisorder" e suas variações obtidas pelo MeSH. Foram incluídas Revisões Sistemáticas e Meta-análises, publicadas no último ano e na língua inglesa, encontrando 14 artigos, sendo quatro utilizados neste trabalho. A seleção foi através da leitura dos abstracts e, posteriormente, leitura completa, selecionando aqueles que abordavam o tema.

\section{REVISÃO BIBLIOGRÁFICA}

Após a leitura do acervo selecionado, pôde-se inferir que o possível estado da arte sobre a incidência de DOG na Covid-19 reflete que sua manifestação é um marcador na maioria das infecções, podendo propiciar um tratamento precoce e uma melhor recuperação (AGYEMAN AA, et al., 2020; COSTA KVTD, et al., 2020; HOANG MP, et al., 2020; TONG JY, et al., 2020). Acredita-se também que, a presença de DOG seja um indicador de grau leve a moderado da infecção, corroborando assim com o combate e o controle da doença (COSTA KVTD, et al, 2020).

Ademais, a recuperação dos pacientes com DOG, apresenta um prazo médio de 2 semanas após o seu contágio, todavia, há relatos de pacientes que não apresentaram recuperação mesmo após o fim da infeção e do período médio (AGYEMAN AA, et al., 2020; COSTA KVTD, et al., 2020;).

\section{CONSIDERAÇÕES FINAIS}

Pode-se concluir que, os pacientes com sintomas de DOG moderados devem permanecer em isolamento social, mesmo sem diagnóstico confirmado, pois esses sintomas estão relacionados com a Covid-19. Cabe ressaltar que sua fisiopatologia ainda é incerta, acredita-se que ocorre através da Enzima Conversora de 
Angiotensina 2, que age como receptor do vírus, levando-o até o Bulbo Olfatório, afetando os neurônios olfativos.

\section{REFERÊNCIAS}

1. AGYEMANAA, et al. Smell and taste dysfunction in patients with COVID-19: A systematic review and metaanalysis. Mayo Clinic Proceedings, 2020; 95(8):1621-31.

2. COSTA KVTD, et al. Olfactoryand taste disorders in COVID-19: A systematic review. Brazilian Journal ofOtorhinolaryngology, 2020; 86(6):781-92.

3. HOANG MP, et al. Olfactory and gustatory dysfunctions in COVID-19 patients: A systematic review and meta-analysis. Asian Pacific Journal ofAllergy and Immunology, 2020; 38(3):162-9.

4. TONG JY, et al. The prevalence of olfactory and gustatory dysfunction in COVID-19 patients: A systematic review and meta-analysis. Otolaryngology-Head and Neck Surgery, 2020; 163(1):3-11. 
RESUMO SIMPLES: Revisão Bibliográfica

Título: Riscos da adenotonsilectomia e adenotonsilotomia em pacientes pediátricos

Autor/coautores: Aline Batista Brighenti dos Santos, Miguel Eduardo Guimarães Macedo, Alice Filgueiras Netto, Julia Abrahão Lopes.

Instituição: Faculdade de Ciências Médicas e da Saúde de Juiz de Fora (FCMS/JF), Juiz de Fora - MG.

Palavras-chave: Adenotonsilectomia; Adenotonsilotomia, Pediátrico.

\section{INTRODUÇÃO}

A adenotonsilectomia tradicional (ATE), procedimento de retirada total das tonsilas palatinas e adenoides, está entre os procedimentos mais comuns em crianças. Gera controvérsias entre os profissionais pois está muito associada a fortes sangramentos e a dor elevada no pós operatório (BLACKSHAW H, et al., 2020). Já a adenotonsilotomia (ATT), retirada parcial do tecido, é um método alternativo que vem se tornando mais comum em países europeus por ser considerado mais seguro e eficaz (BORGSTROM A et al., 2019).Dessa forma, cabe-se comparar os riscos da ATT e da ATE em pacientes pediátricos.

\section{OBJETIVO}

Realizar uma revisão bibliográfica da literatura científica, comparando os procedimentos ATT e a ATE, avaliando a possível redução da morbidade pós-operatória e das complicações na ATT especificamente em pacientes pediátricos.

\section{MÉTODO}

Realizou-se revisão sistemática na base de dados MedLine, com descritores "adenotonsillectomy"; "adenotonsillotomy"; "pediatric". Critérios de inclusão: Ensaios Clínicos Controlados e Randomizados (ECCRs) e Estudos de Meta-Análise, em crianças até 18 anos de idade, nos últimos 5 anos e na língua inglesa; critérios de exclusão: não elegibilidade para inclusão. Foram encontrados 28 estudos, sendo 4 deles selecionados de maior impacto e relevância.

\section{REVISÃO BIBLIOGRÁFICA}

Um ECCR duplo cego comparando dois grupos: ATE e ATT, comprovou que a perda sanguínea perioperatória no centro cirúrgico foi significativamente maior no grupo ATE; (média \pm DP) 55,1 $\pm 33,9 \mathrm{ml}$ (ATE) versus $28,6 \pm 15,6 \mathrm{ml}$ (ATT), $p<0,001$. O primeiro dia sem dor ocorreu na mediana do dia (intervalo interquartil) 8 (5-10) no grupo ATE e no dia 5 (3-8) no grupo ATT, $p=0,021$, e o primeiro dia com dor reduzida para VAS $\leq 5: 1(0-4,5)$ após ATE e $0(0-1)$ após ATT, $p=0,007$ (BORGSTROM A, et al., 2019).

Em outro ECCR, comparando os grupos, o sangramento pós-operatório diferiu significativamente $(\mathrm{p}=$ 0,048), $8 \%$ dos pacientes do grupo ATE sofreram sangramento pós-operatório retardado e $0 \%$ no ATT (KORDELUK S, et al.2016). Ademais, uma meta-análise de 25 estudos e total de 8.078 participantes mostra que os pacientes que realizaram ATT retornaram à dieta $(p=0,0135)$ e atividades normais $(p=0,0451)$ mais rapidamente no período pós-operatório que aqueles no grupo ATE (LEE H, et al., 2017).

\section{CONSIDERAÇÕES FINAIS}


A ATE pode ser considerada como um bom procedimento alternativo à ATT, uma vez que gera menos complicações, riscos e sintomas pós cirúrgicos. Assim, por ser uma intervenção menos invasiva, permite gerar melhor qualidade de vida para as crianças com indicação.

\section{REFERÊNCIAS:}

1. BLACKSHAW H, et al. Tonsillectomy versus tonsillotomy for obstructive sleep-disordered breathing in children. Cochrane Database Syst Rev. 2020; 29: 4(4).

2. BORGSTRÖM A, et al. Postoperativepainandbleedingafteradenotonsillectomy versus adenotonsillotomy in pediatricobstructivesleepapnea: an RCT. EurArch Otorhinolaryngol, 2019: 276(11).

3. KORDELUK S, GOLDBART A, NOVACK L, et al. Randomizedstudycomparinginflammatory response aftertonsillectomy versus tonsillotomy. EurArch Oto-Rhino-Laryngol. 2016; 273(11): 3993-4001. doi: 10.1007/s00405-016-4083-5.

4. LEE H, et al. The Safety and Efficacy of Powered Intracapsular Tonsillectomy in Children: A Metaanalysis. The safety and efficacy of powered intracapsular tonsillectomy in children: A meta-analysis. The Laryngoscope. 2017; 128(3): 732-744. doi:10.1002/lary.26886. 
RESUMO SIMPLES: Revisão Bibliográfica

Título: Eficácia do uso de pregabalina no controle da dor no pós-operatório em cirurgias cérvicofaciais: uma revisão sistemática

Autor/coautores: Nara de Carvalho Andrade Soares Magaldi', Leonardo Ramos Ribeiro de Oliveira², Gabriela Coelho Couto Rocha Corrêa ${ }^{1}$, Maria Vitória Figueiredo Martins', Nathane Barbosa Xavier¹.

Instituições: ${ }^{1}$ Faculdade de Ciências Médicas e da Saúde de Juiz de Fora (FCMS/JF), Juiz de Fora - MG; ${ }^{2}$ Hospital Evandro Ribeiro, Juiz de Fora - MG.

Palavras-chave: Pregabalina, Dor, Cirurgias cérvicofaciais.

\section{INTRODUÇÃO}

As cirurgias cérvicofaciais evoluíram drasticamente ao longo dos anos. Apesar da alta densidade tecnológica e dos procedimentos de alta complexidade empregados, a dor no pós-operatório ainda é um problema comum, sendo de difícil manejo na Otorrinolaringologia (CHEN N, et al., 2018). Estudos recentes discutem sobre emprego da pregabalina, um anticonvulsivante comumente utilizado no controle da dor crônica persistente, para o manejo eficiente da dor em cirurgias otorrinolaringológicas (HWANG, SH et al., 2016). Sendo assim é necessário reconhecer o grau de eficácia do uso deste medicamento visando a diminuição da dor em pós-operatórios cérvicofaciais.

\section{OBJETIVO}

Revisar o emprego do anticonvulsivante pregabalina, assim como avaliar o grau de sua eficácia no tratamento da dor aguda durante o pós-operatório das cirurgias cérvicofaciais e os seus efeitos adversos.

\section{MÉTODO}

Trata-se de uma revisão sistemática, tendo como referência a base de dados PubMed. Foram analisados estudos qualitativos descritivos publicados nos últimos 5 anos. Incluiu-se estudos de Meta-análise, de Revisão e de Revisão Sistemática e excluiu-se artigos de estudos em animais. Dentre os 11 artigos encontrados, foram selecionados cinco, devido a sua relevância e correlação mais precisa com o tema desta revisão. Os descritores utilizados foram: "Pregabalin", "pain", "postoperative", "surgery", "otorhinolaryngology".

\section{REVISÃO BIBLIOGRÁFICA}

O uso da medicação pregabalina durante o período pré-operatório possibilitou alívio da dor durante as primeiras 24 horas pós-operatórias dos pacientes que foram submetidos à cirurgia cérvicofacial. Não foram relatadas novas incidências de efeitos colaterais inesperados, exceto os efeitos relacionados à visão turva (PARK JE, et al., 2016).

Em um ensaio clínico randomizado e duplo-cego, realizado com indivíduos do sexo mascuino e feminino entre 18 e 50 anos de idade, foram avaliados trinta e dois pacientes que utilizando pregabalina uma hora antes da indução pré-anestésica, obtiveram uma pontuação média nas escalas Visual Analouge Scale e Riker sedation-agitation scale menor em comparação ao grupo controle no qual trinta e três participantes completaram o estudo (POURFAKHR P, et al., 2019). Há controvérsias no momento da escolha da dose ideal, porém foi observado que uma dose única de $150 \mathrm{mg}$ proporcionou menor uso de analgesia complementar durante o pós-operatório (HERMOSO LS, et al., 2017).

\section{CONSIDERAÇÕES FINAIS}


Nesta revisão sistemática os artigos analisados avaliaram a eficácia do uso de pregabalina para o controle da dor no pós-operatório de cirurgias cérvicofaciais. Concluiu-se, que a administração no pré-operatório reduziu significativamente a dor do pós-operatório, o consumo de analgesia complementar e ainda não apresentou efeitos adversos graves.

\section{REFERÊNCIAS}

1. CHEN N, et al. "Does a single dose of pregabalin help with postoperative pain after septoplasty." The Laryngoscope, 2018; 128(5): 1023-4.

2. HWANG SH, et al. "The efficacy of gabapentin/pregabalin in improving pain after tonsillectomy: A metaanalysis." The Laryngoscope, 2016; 26(2): 357-66.

2. HERMOSO LS, et al. "Oral pregabalin for acute pain relief after cervicofacial surgery: a systematic review." Clinical oral investigations, 2018; 22(1): 119-129.

3. PARK IJ, et al. "Does preoperative administration of gabapentin/pregabalin improve postoperative nasal surgery pain?." The Laryngoscope, 2016; 126(10): 2232-41.

6. POURFAKHR P, et al. "Low-dose preoperative pregabalin improves postoperative pain management in septorhinoplasty surgery: a double-blind randomized clinical trial." European archives of otorhinolaryngology: official journal of the European Federation of Oto-Rhino-Laryngological Societies (EUFOS): affiliated with the German Society for Oto-Rhino-Laryngology - Head and Neck Surgery, 2019; 276(8): 2243-29. 
RESUMO SIMPLES: Revisão Bibliográfica

Título: Vertigem Paroxística Benigna da Infância como precursora de enxaqueca em adolescentes e adultos

Autor/coautores: Amanda Mendes Lourenço, Júlia Melo Pereira, Rebecca Maria Campos Diniz, Beatriz Soares Montandon, Miguel Eduardo Guimarães Macedo.

Instituição: Faculdade de Ciências Médicas e da Saúde de Juiz de Fora (FCMS/JF), Juiz de Fora - MG.

Palavras-chave: Benign paroxysmal vertigo of childhood, Migraine disorders.

\section{INTRODUÇÃO}

A vertigem paroxística benigna da infância (BPVC) é considerada uma das causas mais comuns de vertigem em crianças e é caracterizada por ataques curtos e repentinos de desequilíbrio e vertigens, que possuem resolução espontânea em minutos ou horas (LEE JD, et al., 2017). Os episódios de vertigem geralmente se resolvem espontaneamente com o passar da idade, entretanto, devido às múltiplas características, como periodicidade, presença de sintomas de enxaqueca em alguns pacientes, alta incidência da mesma em adultos com uma história de BPVC e uma alta taxa de história familiar de enxaqueca, alguns estudos descrevem a BPVC como um precursor da enxaqueca ou equivalente (BRODSKY J, et al., 2018).

\section{OBJETIVO}

Investigar e analisar, por meio de uma revisão sistemática, a relação entre a Vertigem Paroxística Benigna da Infância (BPVC) com a enxaqueca em adolescentes e adultos, analisando uma possível progressão.

\section{MÉTODO}

Realizou-se revisão sistemática na base National Library of Medicine (MEDLINE), em dezembro/2020, por meio dos descritores: Benign Paroxysmal Vertigo of Childhood e Migraine disorders. Foram incluídos artigos originalmente em inglês, dos últimos cinco anos, em humanos e excluídos estudos com métodos pouco claros ou mal descritos. Assim, através de uma busca continuada, quatro artigos fizeram parte do escopo e análise final.

\section{REVISÃO BIBLIOGRÁFICA}

A International Classification of Headache Disorders (ICHD) lista a BPVC como uma síndrome periódica da infância precursora da enxaqueca. Foi observado, também, que a prevalência de enxaqueca em adultos é duas vezes mais comum em pessoas com história da patologia. Ademais, os adultos enxaquecosos têm três vezes mais chances de ter um histórico de BPVC em comparação com aqueles sem enxaqueca, e metade dos pacientes com BPVC tem história familiar de enxaqueca (BRODSKY JR, et al., 2016).

Quanto à BPVC, uma tendência para uma diminuição dos episódios é observada, embora alguns casos progridam para enxaqueca na adolescência (SOMMERFLECK PA, et al., 2016). Em estudo com análise de dados de 39 pacientes com diagnóstico de BPVC, vários destes $(15,4 \%)$ exibiram progressão de BPVC para Vestibular Migraine (VM), um fenômeno que chamamos de "marcha vestibular" (BRODSKY J, et al., 2016).

\section{CONSIDERAÇÕES FINAIS}

Os estudos analisados revelaram que a Vertigem Paroxística Benigna da Infância apresenta evidências de ser um precursor da enxaqueca nesses pacientes. Entretanto, por não ser uma condição homogênea, 
torna-se difícil aconselhar famílias sobre os prognósticos desse distúrbio. Dessa forma, não há evidências suficientes que mostrem a incidência real e fatores de risco para tal progressão.

\section{REFERÊNCIAS}

1. BRODSKY J, et al. Benign paroxysmal migraine variants of infancy and childhood: Transitions and clinical features. Eur J Paediatr Neurol, 2018; 22(4):667-673.

2. BRODSKY JR, et al. Evaluation and management of vestibular migraine in children: Experience from a pediatric vestibular clinic. Eur J of Pediatr Neurol, 2016; 20(1):85-92.

3. LEE JD, et al. Prevalence of vestibular and balance disorders in children and adolescents according to age: A multi-center study. Int J Pediatr Otorhinolaryngol, 2017; 94:36-39.

4. SOMMERFLECK PA, et al. Balance disorders in childhood: Main etiologies according to age. Usefulness of the video head impulse test. Int J Pediatr Otorhinolaryngol, 2016; 87:148-53. 
RESUMO SIMPLES: Revisão Bibliográfica

Título: Prevenção da perda auditiva induzida por ruído (PAIR) ocupacional

Autor/coautores: Júlia Melo Pereira, Rebecca Maria Campos Diniz, Beatriz Soares Montandon, Amanda Mendes Lourenço, Miguel Eduardo Guimarães Macedo.

Instituição: Faculdade de Ciências Médicas e da Saúde de Juiz de Fora (FCMS/JF), Juiz de Fora - MG.

Palavras-chave: Perda auditiva induzida por ruído, Ocupacional, Prevenção.

\section{INTRODUÇÃO}

A perda auditiva induzida por ruído (PAIR) ocupacional é uma problemática de enorme significância no cenário mundial, sendo a segunda doença ou lesão ocupacional autorreferida mais recorrente (TIKKA C, et al., 2017). Tal comorbidade representa entre 7 e $21 \%$ da perda auditiva entre os trabalhadores (LIE A, et al., 2015), além de ser permanente, incurável e de progressão lenta com a exposição contínua a elevados níveis de ruído. Ademais, a PAIR ocupacional ocasiona uma série de prejuízos emocionais, físicos e econômicos para o trabalhador e para a sociedade (MCCULLAGH MC, et al., 2016).

\section{OBJETIVO}

Investigar, através de uma revisão da literatura científica, as formas e a eficácia da prevenção da perda auditiva induzida por ruído (PAIR) resultante da exposição ocupacional, analisando fatores como adesão e preferência dos trabalhadores.

\section{MÉTODO}

Realizou-se revisão sistemática nas bases PubMed e SciELO, durante o período de dezembro de 2020. Os descritores utilizados foram: Noise Induced Hearing Loss, Noise-Induced Hearing Loss e Acoustic Trauma, encontrados no MeSh. Foram incluídos Ensaios Clínicos Controlados e Randomizados, Meta-Análises e Revisões Sistemáticas, dos últimos cinco anos. Foram excluídos estudos com métodos mal descritos. Incialmente encontrou-se 42 artigos, dos quais foram selecionados os 3 de maior impacto e relevância.

\section{REVISÃO BIBLIOGRÁFICA}

Um estudo que analisou 29 artigos científicos, com rígidos critérios de inclusão, aponta que uma legislação mais rigorosa reduz em aproximadamente $4,5 \mathrm{~dB}$ no nível de ruído e que a proteção auditiva pessoal diminui essa exposição em cerca de $20 \mathrm{~dB}$ (TIKKA C, et al., 2017).

Uma revisão sistemática que investigou 187 estudos sobre audição em várias profissões afirma que, em razão da melhor regulação e do uso de equipamentos de proteção, a PAIR ocupacional tem sido um problema menos frequente nos países desenvolvidos. Porém, essa tendência não se aplica aos países em desenvolvimento, nos quais a exposição a elevados níveis de ruído ainda é significativa (LIE A, et al., 2015).

Por fim, um estudo realizado com 491 trabalhadores agrícolas evidenciou que o sortimento de protetores auditivos se caracteriza como forma mais eficaz de adesão à proteção auditiva pessoal em comparação com mensagens informativas (MCCULLAGH MC, et al., 2016).

\section{CONSIDERAÇÕES FINAIS}

A PAIR ocupacional apresenta variadas formas eficazes de prevenção, cujo acesso está relacionado às condições socioeconômicas do país de origem do trabalhador. No entanto, para garantir a adesão à essas 
medidas protetivas, os métodos preventivos devem ser de fácil acesso ao trabalhador e se adequar à sua individualidade.

\section{REFERÊNCIAS}

1. LIE A, et al. Occupational noise exposure and hearing: a systematic review. Int Arch Occup Environ Health, 2016; 89(3): 351-72.

2. MCCULLAGH MC, et al. Effects of interventions on use of hearing protectors among farm operators:a randomized controlled trial. Int J Audiol, 2016; 1(0): S3-12.

3. TIKKA C, et al. Interventions to prevent occupational noise-induced hearing loss. Cochrane Database Syst Rev, 2017; 7(7): CD006396. 
RESUMO SIMPLES: Revisão Bibliográfica

Título: Manejo Clínico de Tosse Aguda em Bebês e Crianças

Autor/coautores: Beatriz Soares Montandon, Miguel Eduardo Guimarães Macedo, Rebecca Maria Campos Diniz, Júlia Melo Pereira, Amanda Mendes Lourenço.

Instituição: Faculdade de Ciências Médicas e da Saúde de Juiz de Fora (FCMS/JF), Juiz de Fora - MG.

Palavras-chave: Tosse, Criança, Infecção de via aérea superior.

\section{INTRODUÇÃO}

O reflexo da tosse é iniciado pela irritação dos receptores presentes no trato respiratório através de estímulos químicos ou mecânicos. As fibras- $C$ são as principais responsáveis pela indução da tosse por estímulos químicos, enquanto os receptores de adaptação rápida (RARs) e os receptores de estiramento de adaptação lenta (SARs) são os principais mecanoreceptores envolvidos nesse reflexo (RODRIGUES MS e GALVÃO IM, 2017). O conhecimento desses mecanismos fisiopatológicos é essencial, já que quadros de tosse aguda desencadeados por infecções de via aérea superior (IVAS) são um dos principais motivos de consulta médica infantil (WILKINSON R, et al., 2019).

\section{OBJETIVO}

Analisar e sintetizar, por meio de uma revisão sistemática, as evidências existentes a respeito do manejo clínico de pacientes pediátricos que apresentam quadro clínico de tosse aguda em decorrência de IVAS.

\section{MÉTODO}

Realizou-se essa revisão sistemática através de consulta na National Library of Medicine (MEDLINE), em dezembro de 2020, com os descritores: cough, child, upper respiratory infection e suas variações obtidas no Medical Subject Headings (MeSH). Foram incluídos estudos dos últimos cinco anos que envolviam crianças (nascimento-18 anos) e excluídos estudos com métodos pouco claros. Foram encontrados 14 estudos, através dos quais realizou-se busca continuada, resultando na seleção de cinco artigos.

\section{REVISÃO BIBLIOGRÁFICA}

Um estudo analisou 257 crianças a fim de realizar uma associação entre características clínicas e presença de infecção viral. A presença de tosse e febre em decorrência de IVAS indicou uma probabilidade de infecção por vírus respiratório de 76,8\%, o que contradiz a prescrição de antibióticos (KOOL M, et al., 2015).

Outro estudo, realizado com 330 crianças afetadas com IVAS, comparou crianças tratadas com antitussígenos com crianças tratadas com antibióticos, evidenciando diferença estatisticamente significativa $(p<0,05)$ na resolução da tosse em favor dos antitussígenos (ZANASI A, et al., 2016).

Um terceiro estudo avaliou crianças com diagnóstico de IVAS, apontando que medicamentos isentos de prescrição (MIP's) para tosse são indicados por médicos em cerca de $67,4 \%$ dos casos. No entanto advertências nacionais e internacionais relatam baixa eficácia e toxicidade desses medicamentos em bebês e crianças pequenas (TURAN C, et al., 2020).

\section{CONSIDERAÇÕES FINAIS}


O manejo clínico de crianças com tosse aguda em decorrência de IVAS não costuma ser eficaz quando prescrito antibióticos e MIP's. Ademais, MIP's para tosse podem gerar efeitos adversos graves em crianças. Concluindo, o manejo clínico mais pertinente para bebês e crianças com tosse associada à IVAS é o uso de terapia sintomática isolada com antitussígenos.

\section{REFERÊNCIAS}

1. KOOL M, et al. Respiratory virus infections in febrile children presenting to a general practice out-of-hours servisse. Eur J Gen Pract, 2015; 21(1): 5-11.

2. RODRIGUES MS, Galvão IM. Aspectos fisiopatológicos do reflexo da tosse: uma revisão da literatura. Revista de Medicina, 2017; 96(3): 172-176

3. TURAN C, et al. Physician's prescription pattern in young infants with upper respiratory infections/cough and cold in emergency department. Pak J Med Sci, 2020; 36(2): 166-170.

4. WILKINSON R, et al. Pediatric Care Provided at Urgent Care Centers in the United States: Compliance With Recommendations for Emergency Preparedness. Pediatr Emerg Care, 2016; 32(2): 1-5

5. ZANASI A, et al. Prospective study of the efficacy of antibiotics versus antitussive drugs for the management of URTI-related acute cough in children. Multidiscip Respir Med, 2016; 11(29): 2-6. 
RESUMO SIMPLES: Revisão Bibliográfica

Título: Narcolepsia: Uso de Oxibato de Sódio na população pediátrica - Revisão Sistemática

Autores: Mariana Carneiro Takeuchi, Miguel Eduardo Guimarães Macedo, Víctor de Oliveira Costa, Bruna dos Santos Rocha Schiavon.

Instituição: Faculdade de Ciências Médicas e da Saúde de Juiz de Fora (FCMS/JF), Juiz de Fora - MG.

Palavras-chave: Narcolepsia, Oxibato de sódio, Pediatria.

\section{INTRODUÇÃO}

Narcolepsia é uma desordem neurológica crônica com início comumente na infância, com média de nove anos (PILLEN S, et al., 2017). Por se tratar de uma condição incurável, o tratamento é sintomático e inclui medicações tal como o oxibato de sódio (SO) (CHEN C, et al., 2020). Entretanto, atualmente, nenhuma droga é aprovada para tratar narcolepsia em crianças e adolescentes; mas devido à eficácia do uso do SO em adultos, o uso terapêutico deste na faixa etária pediátrica torna-se cada vez mais uma realidade necessária (MAYER G, et al., 2018).

\section{OBJETIVO}

Analisar a segurança do uso de SO no tratamento da narcolepsia na pediatria, assim como confirmar a eficácia desse fármaco no que tange à diminuição dos sintomas gerados pela síndrome nessa faixa etária.

\section{MÉTODO}

Revisão sistemática realizada no PubMed, Embase, Cochrane, Web of Science, usando termos: "Narcolepsy, "Sodium oxybate" e "Pediatric". Selecionados estudos publicados entre 01/12/2015 e 01/12/2020. Foram incluídos aqueles que abordavam o uso de SO na pediatria e excluídos os que não tinham o foco nessa população. 33 artigos foram selecionados para leitura, sendo que 28 foram excluídos, pois não estavam dentro dos critérios de inclusão. 5 foram incluídos na síntese qualitativa.

\section{REVISÃO BIBLIOGRÁFICA}

O número de pacientes pediátricos analisados variou de 24 a 106 nos estudos, com idade menor que 18 anos, sendo evidenciado eficácia no uso e demonstrando melhora na população com significância estatística $(p<0,05)$. Participantes que receberam placebo ou que randomicamente foram retirados da dose de SO (51\%) apresentaram aumento de ataques catapléticos (12.7/semana) quando comparado com aqueles que mantiveram o tratamento.

Poucos indivíduos $(0,01 \%)$ apresentaram efeitos adversos graves com o uso, como ideação suicida $(0,009 \%)$ e psicose aguda $(0,009 \%)$, sendo revertidos com o cessar do uso; os mais frequentes foram enurese (18-25\%), náuseas, vômitos e cefaleia (> 5\%) (FILARDI M, et al., 2018; PLAZZI G, et al., 2018). Ademais, o peso é o principal fator intrínseco que afeta a farmacocinética do SO; logo, a titulação da dose para pediatria deve levar tal variável em consideração (CHEN C, et al., 2020).

\section{CONSIDERAÇÕES FINAIS}

O SO foi considerado uma droga eficaz no tratamento da narcolepsia em crianças e adolescentes. O baixo percentual de efeitos adversos graves indicou que o perfil de segurança é consistente com aquele observado em adultos, sendo assim uma opção de terapêutica. 


\section{REFERÊNCIAS}

1. CHEN C, et al. Population and noncompartmental pharmacokinetics of sodium oxybate support weightbased dosing in children and adolescents with narcolepsy with cataplexy. Clin Trans Sci 2020; 13: 932-40.

2. FILARDI M, et al. In-field assessment of sodium oxybate effect in pediatric type 1 narcolepsy: an actigraphic study. Sleep 2018; 41(6).1-7.

3. MAYER G, et al. Long-term compliance, safety, and tolerability of sodium oxybate treatment in patients with narcolepsy type 1: a postauthorization, noninterventional surveillance study. Sleep. 2018; 41(9): 1-8.

4. PILLEN S, et al. Cataplexy and its mimics: clinical recognition and management. Curr Treat Options Neurol 2017; 19: 23-43.

5. PLAZZI G, et al. Treatment of paediatric narcolepsy with sodium oxybate: a double-blind, placebocontrolled, randomised-withdrawal multicentre study and open-label investigation. Lancet Child Adolesc Health. 2018; 2(7):483-494. 
RESUMO SIMPLES: Revisão Bibliográfica

Título: Perda auditiva induzida por ruídos e sua nocividade no ambiente de trabalho: uma revisão sistemática da literatura

Autores/coautores: Jemima Ferreira Coelho ${ }^{1}$, Ana Sílvia Menezes Bastos ${ }^{1}$, Laura Pires Ligeiro ${ }^{1}$, Indiara Íris de Oliveira Araujo ${ }^{1}$, Danielle Raphaela Alves².

Instituição: ${ }^{1}$ Universidade de Vassouras (UV), Vassouras - RJ; ${ }^{2}$ Centro Universitário do Espírito Santo (UNESC), Colatina - ES.

Palavra-chave: Perda auditiva induzida por ruídos, Perda auditiva permanente, Trauma acústico.

\section{INTRODUÇÃO}

A perda auditiva induzida por ruído (PAIR) está relacionada ao ambiente de trabalho. O ruído quando presente por períodos prolongados, de forma crônica, leva a perda progressiva e irreversível da audição. Mesmo com a presença de equipamentos de proteção individual (EPI) ocorre trauma acústico. Já a disfunção vestibular leva a tonturas e dores de cabeça. A destruição do Órgão de Corti leva a otalgia, zumbidos, e a longo prazo a perda permanente da audição (TRUNG N, et al., 2017). A investigação é iniciada por um formulário onde é interrogado cada um dos sintomas, seguido de otoscopia para descartar hipoacusias secundárias, finalizando com a audiometria tonal limiar (CUNHA AP, et al., 2019).

\section{OBJETIVO}

Gerar conhecimento a respeito dos sinais e sintomas, seu início, duração, frequência, periodicidade apresentados pelos pacientes que foram expostos a ruídos, para um diagnóstico precoce que contribuirá para uma prática clínica de qualidade.

\section{MÉTODO}

Trata-se de uma revisão sistemática de literatura especializada onde foram buscados periódicos publicados entre 2015-2020, as palavras chave de busca foram: perda auditiva induzida por ruídos; nas bases de dados digitais: Google Acadêmico, PubMed e Scielo. Foram encontrados 6 artigos sendo utilizados 4 destes. Foram incluídos artigos que abordam a PAIR em trabalhadores industriais expostos cronicamente mesmo em uso de EPI's, e excluída perda auditiva fora do trabalho.

\section{REVISÃO BIBLIOGRÁFICA}

O trabalhador quando exposto a ambientes laborais ruidosos, de forma prolongada e crônica leva a lesões auditivas irreversíveis, que podem se estender do meato acústico externo até o órgão de Corti, acarretando um comprometimento neurossensorial. Os sintomas otológicos mais relatados e indicativos de perda auditiva com base no formulário são: tinnitus, dificuldade de compreensão da fala, hipoacusia e tonturas.

O caráter insidioso e progressivo da doença como demonstrado pelos estudos já conduzidos viabiliza correlacionar a presença da queixa sintomatológica com a extensão da gravidade do trauma acústico. (TRUNG N, et al., 2017). Atualmente, a maior dificuldade no diagnóstico da PAIR nas fases iniciais é a ausência de sintomas. Portanto, postergar o diagnóstico da perda auditiva por conta da escassez clínica tem impacto negativo na qualidade de vida do indivíduo (TIKKA C, et al., 2020) (GONÇALVES CGO e FONTURA FP, 2018).

\section{CONSIDERAÇÕES FINAIS}


É possível depreender que a exposição prolongada aos ruídos gera sintomas que culminam na perda irreversível da audição, impactando significativamente na qualidade de vida do trabalhador. Dessa forma, é preciso incentivar o uso de EPI's, diminuir a fonte emissora de ruídos e monitorar de forma ativa e contínua os trabalhadores, visando primordialmente a conservação da sua função auditiva.

\section{REFERÊNCIAS}

1. CUNHA AP, et al. Perda Auditiva Induzida Pelo Ruído Ocupacional. Revista Multidisciplinar, 2019; 16: 507520.

2. GONÇALVES CGO, FONTURA FP. Educational interventions on prevention of hearing loss at work: an integrative review. Revista Brasileira de Saúde Ocupacional, 2018; 43: e5s

3. TIKKA C, et al. Cochrane Method for systematic review and meta-analysis of intervention stopreventoccupation noise-induced hearing loss - abridged. CoDAS, 2020; 2: e20190127

4. TRUNG NLE, et al. Current insights in noise-induced hearing loss: a literature review of the underlying mechanism, pathophysiology, asymmetry, and management options. JournalofOtolaryngology - Head \&NeckSurgery, 2017, 41: 1-15. 
RESUMO SIMPLES: Revisão Bibliográfica

Título: Um novo olhar sobre a surdez súbita: uma revisão sistemática da literatura

Autor/coautores: Laura Pires Ligeiro', Ana Sílvia Menezes Bastos[A1] ${ }^{1}$, Jemima Ferreira Coelho', Indiara Íris de Oliveira Araujo', Danielle Raphaela Alves².

Instituição: Universidade de Vassouras (UV), Vassouras -RJ1; Centro Universitário do Espírito Santo (UNESC), Colatina - ES ${ }^{2}$.

Palavras-chave: Perda auditiva súbita, surdez súbita.

\section{INTRODUÇÃO}

A surdez súbita (SS) se caracteriza por uma perda auditiva $>30 \mathrm{db}$ em no mínimo três frequências tonais adjacentes se instalar subitamente ou até 3 dias de duração. Decorre de uma alteração na pressão hidrostática que modifica a estimulação nervosa da cóclea (BARRETO MQSC, et al., 2016). A SS representa um sintoma sem uma etiologia própria, estando presente em várias doenças diferentes, desde o Schwanoma Vestibular (SV) até a hemorragia intra-labiríntica e por pouco se saber sobre seus mecanismos ainda é muito discutida. Nesse sentido, o indivíduo acometido não recebe um tratamento específico, o que acaba impedindo suas interações sociais e favorecendo ao isolamento (MAIA NPD, et al., 2019).

\section{OBJETIVO}

Sintetizar a problemática da SS com as publicações dos últimos anos, tendo em vista as suas diversas etiologias, fisiopatologia, clínica e o tratamento, para construir um entendimento alicerçado e uniforme gerando conhecimento para uma prática clínica otorrinolaringológica de qualidade.

\section{MÉTODO}

Este artigo se baseia em uma revisão sistemática de literatura especializada onde a questão da SS foi explorada nas bases de dados digitais: PubMed e Scielo com as seguintes palavras-chave: perda auditiva súbita, surdez súbita. Foram encontradas 10 publicações entre 2015-2020 em português e inglês sendo utilizados apenas 4 destes. Foram incluídos artigos que abordam o tema da SS e excluídos os que não se enquadram no tema.

\section{REVISÃO BIBLIOGRÁFICA}

A surdez súbita é uma doença que não possui uma entidade nosológica própria, assim foram criadas quatro hipóteses teóricas para tentar explicar sua fisiopatologia, sendo elas: infecção viral, imunológica, ruptura de membranas e distúrbio circulatório. As duas primeiras hipóteses são as mais bem aceitas, já as duas últimas ainda são objetos de muito estudo.

Com relação ao prognóstico seis fatores são determinantes para a recuperação auditiva final: o tempo decorrido entre o início do sintoma e o diagnóstico, o tipo de curva audiometria tonal, a severidade da surdez inicial, a velocidade de hemossedimentação, tonturas severas e o exame vestibular com hiporreflexia (AKIL F, et al., 2018). Devido ao fácil manuseio e baixo custo os corticoides são muito utilizados, assim como os vasodilatadores, pois melhoram a perfusão sanguínea da cóclea, e o metabolismo para a regeneração (YU, GH, et al., 2018).

\section{CONSIDERAÇÕES FINAIS}


É possível depreender que a SS tem muitas divergências literárias sendo necessário realizar um estudo controlado-randomizado. Como o uso de corticoides se já se provou eficaz na redução do tempo de convalescência, a hipótese de etiologia viral e imunológica são hoje as mais aceitas. Outro consenso é com relação ao uso da ressonância magnética para o diagnóstico e diagnóstico diferencial como no caso do Schwanoma vestibular.

\section{REFERÊNCIAS}

1. AKIL F, et al. Simultaneousidiopathic bilateral suddenhearingloss - characteristicsand response totreatment. 2018: (1): 95-101.

2. BARRETO MQSC, et al. Intratympacniccorticosteroid for suddenhearingloss: does it reallyWork?, 2016; (3): 353-364.

3. MAIA NPD, et al. Vestibular evokedmyogenicpotentials in theprognosisofsuddenhearingloss- a systematicreview, 2019; 86: 247-254.

4. $\mathrm{YU} \mathrm{GH}$, et al. A comparisonof single-dose andmultipledivideddaily-dose oral steroids for suddensensorineural, 2018; 85: 733-738. 
RESUMO SIMPLES: Revisão Bibliográfica

Título: Manifestações Clínicas do Refluxo Laringofaríngeo: uma revisão sistemática

Autores/coautores: Mauricio Silva de Moraes Souza, Bernardo Valle Zanetti, Daniel Camargo de Andrade, Milla Giancristofaro Dutra, Miguel Eduardo Guimarães Macedo.

Instituição: Faculdade de Ciências Médicas e da Saúde de Juiz de Fora (FCMS/JF), Juiz de Fora - MG.

Palavras-chave: Manifestação, Refluxo gastroesofágico, Refluxo laringofaríngeo.

\section{INTRODUÇÃO}

O refluxo ácido para as vias aéreas é conhecido como refluxo laringofaríngeo (RLF) (Ricci G, et al., 2020). É uma das manifestações extraesofágicas mais comuns da doença do refluxo gastroesofágico (DRGE) e tem como algumas de suas causas o esvaziamento gástrico retardado e a depuração esofágica significativamente retardada (RICCI G, et al., 2020; WU ZH, et al., 2018). Tem-se aumentado o interesse em pesquisar sobre essa doença em questão devido à gama de manifestações clínicas apresentadas por ela, tais como rinite alérgica e tosse, por exemplo (ALHARETHY S, et al., 2018).

\section{OBJETIVOS}

Analisar, por meio de uma revisão sistemática, algumas manifestações clínicas importantes que tenham como fator de risco o RLF e identificar a associação entre essa doença e alterações no trato aerosuperior.

\section{MÉTODO}

Realizou-se uma revisão sistemática nas bases PubMed e SciELO, em dezembro de 2020, por meio dos descritores "gastroesophageal reflux" e "manifestation"; "refluxo laringofaríngeo", respectivamente. Foram incluídos estudos de artigos originais, dos últimos cinco anos e de língua inglesa e portuguesa. Foram excluídos estudos com métodos pouco claros. Foram encontrados 74 artigos no total, dos quais selecionaremse os 4 de maior impacto e relevância.

\section{REVISÃO BIBLIOGRÁFICA}

Apesar das diversas manifestações clínicas, os estudos em questão analisaram com mais cautela a relação entre o RLF e quatro alterações laríngeas. Alterações da qualidade vocal, como a rouquidão e a tosse são os sintomas mais frequentes no RLF, sendo a principal queixa dos pacientes na consulta médica. Essas manifestações clínicas ocorrem devido a aspiração de conteúdo gástrico, de modo que haja irritação das pregas vocais e da árvore brônquica, e, como consequência, o paciente manifesta rouquidão e tosse, respectivamente (RICCI G, et al., 2020; SIDHWA F, et al., 2017).

Ademais, a SAHOS está fortemente relacionada a DRGE extraesofágica, uma vez que o fluxo retrógrado do conteúdo gastroduodenal pode causar inflamação das vias aéreas superiores e até mesmo obstrução (WU $\mathrm{ZH}$, et al.,2018). Ainda, parece existir associação entre RLF e rinite alérgica. De acordo com a literatura, o RLF pode ser considerado um cofator no aumento da autopercepção dos pacientes sobre problemas alérgicos (ALHARETHY S, et al., 2018).

\section{CONSIDERAÇÕES FINAIS}

Há evidências suficientes que mostram a correlação entre o RLF e a SAHOS, a rinite alérgica, a tosse e as alterações vocais. Além disso, é válido ressaltar que a DRGE não deve ser negligenciada na prática clínica visto suas diversas manifestações na região laringofaríngea. 


\section{REFERÊNCIAS}

1. ALHARETHY S, et al. Correlation between Allergic Rhinitis and Laryngopharyngeal Reflux. Biomed Res Int, 2018; 29(5): 19-28.

2. RICCI G, et al. Sinais e sintomas de refluxo laringofaríngeo e sua relação com queixas e qualidade vocal. CoDAS, 2020; 32(5).

3. SIDHWA F, et al. Diagnosis and Treatment of the Extraesophageal Manifestations of Gastroesophageal Reflux Disease. Ann Surg, 2017; 265(1): 63-7.

4. WU ZH, et al. The relationship between obstructive sleep apnea hypopnea syndrome and gastroesophageal reflux disease: a meta-analysis. Sleep Breath, 2019; 23(2): 389-97. 
RESUMO SIMPLES: Revisão Bibliográfica

Título: Abordagens Terapêuticas da Misofonia

Autor/coautores: Daniel Camargo de Andrade, Bernardo Valle Zanetti, Mauricio Silva de Moraes Souza, Milla Giancristofaro Dutra, Miguel Eduardo Guimarães Macedo.

Instituição: Faculdade de Ciências Médicas e da Saúde de Juiz de Fora (FCMS/JF), Juiz de Fora - MG.

Palavras-Chave: Abordagens terapêuticas, Misofonia, Misofônico.

\section{INTRODUÇÃO}

A misofonia é uma condição caracterizada pelo forte reflexo comportamental e emocional intolerante a determinados sons, denominados gatilhos misofônicos (como a mastigação), gerando ansiedade, irritação e raiva nos pacientes (AAZH H, et al., 2019; BROUT JJ, et al., 2018; PALUMBO DB, et al., 2018). Comumente, esses descrevem pressão no peito e desejo de acabar com o incômodo (PALUMBO DB, et al., 2018). Isso explicita a necessidade de tratamentos para tal síndrome, tendo em vista que ela costuma acarretar um considerável impacto na vida do paciente, podendo ocasionar isolamento social e prejuízos acadêmicos, diminuindo a qualidade de vida (AAZH H, et al., 2019; PALUMBO DB, et al., 2018).

\section{OBJETIVO}

Revisar a literatura cientifica, através de uma revisão sistemática, sobre as abordagens terapêuticas mais adequadas para o tratamento da misofonia, já que não há cura ou medicamento específico para essa condição.

\section{MÉTODOS}

Durante dezembro/2020, foi realizada uma revisão sistemática tendo como referência o MedLine. Com a utilização dos descritores "misophonia" e "treatment", e suas variações obtidas no MeSH, totalizaram-se 21 artigos. Foram incluídos apenas estudos publicados originalmente em inglês, dos últimos cinco anos e de leitura completa gratuita ("Free full text") e excluídos aqueles que não versavam diretamente sobre a temática analisada. Com isso, quatro artigos fizeram parte da análise final.

\section{REVISÃO BIBLIOGRÁFICA}

$\mathrm{Na}$ ausência de tratamentos farmacológicos, terapias são estudadas e demonstram benefícios no tratamento da misofonia (PALUMBO DB, et al., 2018). Muitas são conduzidas pela descrição de casos individuais ou por relatos com pequeno grupo de participantes (BROUT JJ, et al., 2018). Nesse sentido, duas revisões desse estudo apontam para a terapia cognitivo-comportamental multicomponente (TCC) como benéfica em controlar a raiva na misofonia (AAZH H, et al., 2019; PALUMBO DB, et al., 2018).

Outras opções são a terapia de retreinamento de zumbidos (TRT), para distúrbios de sensibilidade sonora, e a terapia de comportamento dialética (DBT), para casos sem sucesso pela TCC, principalmente em adolescentes (PALUMBO DB, et al., 2018; KAMODY RC e DEL CONTE GS, 2017). Ademais, quadros com níveis mais graves de misofonia podem ser também tratados com a terapia ocupacional e os testes neuropsicológicos (BROUTT JJ, et al., 2018).

\section{CONSIDERAÇÕES FINAIS}


Pode-se concluir que algumas terapias apresentam resultados positivos para a misofonia. Todavia, não há ensaios clínicos controlados e randomizados publicados ratificando tais achados. Assim, estudos de alto nível de evidência científica são necessários para estabelecer a real eficácia dessas terapêuticas.

\section{REFERÊNCIAS}

1. AAZH H, et al. Cognitive Behavioral Therapy For Alleviating The Distress Caused By Tinnitus, Hyperacusis And Misophonia: Current Perspectives. Psychol Res Behav Manag, 2019; 12: 991-1002.

2. BROUT JJ, et al. Investigating Misophonia: A Review of the Empirical Literature, Clinical Implications, and a Research Agenda. Front Neurosci, 2018; $12: 36$.

3. KAMODY RC, DEL CONTE GS. Using Dialectical Behavior Therapy to Treat Misophonia in Adolescence. Prim Care Companion CNS Disord, 2017; 19(5): 17102105.

4. PALUMBO DB, et al. Misophonia and Potential Underlying Mechanisms: A Perspective. Front Psychol, 2018; 9: 953. 
RESUMO SIMPLES: Revisão Bibliográfica

Título: O impacto da pandemia COVID19 na otorrinolaringologia: uma Revisão da literatura

Autor/coautores: Letícia Alves Carvalho ${ }^{3}$, Ana Claudia Elerati de Campos², Fernanda Rodrigues Martins², Lara Esteves Ferreira de Oliveira Almeida ${ }^{2}$, Leonardo Ramos Ribeiro de Oliveira ${ }^{1}$,

Instituições: ${ }^{1}$ Hospital Evandro Ribeiro, Juiz de Fora - MG; ${ }^{2}$ Faculdade de Ciências Médicas e da Saúde de Juiz de Fora (FCMS/JF), Juiz de Fora - MG; ${ }^{3}$ nnstituto Metropolitano de Ensino Superior (IMES/UNIVAÇO), lpatinga - MG

Palavras-chave: Impacto, Covid19, Otorrinolaringologia.

\section{INTRODUÇÃO}

A doença respiratória infecciosa aguda causada pelo coronavírus 2019 (2019-nCoV) é transmitida principalmente por gotículas do trato respiratório e secreções (KUHAR NH, et al., 2020). Assim, devido aos procedimentos geradores de mucosas ou aerossóis, à proximidade ao paciente no exame e à instrumentação frequente no trato respiratório superior, os otorrinolaringologistas são considerados uma população vulnerável à infecção quando comparados a outros profissionais (SOWERBY LJ, et al., 2020) (CIVANTOS AM, et al., 2020). Entretanto, esse risco minimiza-se com a reorganização dos sistemas de saúde e a correta utilização de equipamentos de proteção individual (EPI) (CIVANTOS AM, et al., 2020).

\section{OBJETIVO}

Investigar e analisar, mediante uma revisão da literatura científica os possíveis impactos, atuais e futuros, que a pandemia da COVID19 ocasionou na rotina dos profissionais da saúde da otorrinolaringologia.

\section{MÉTODO}

Esta revisão sistemática foi realizada na base de dados PubMed, através dos descritores: "impact", "COVID19" e "otorhinolaryngology". Foram incluídos estudos publicados entre 27/11/2019 e 27/11/2020, originalmente em inglês, realizados em humanos e em adultos. Todos os estudos que não preenchiam esses critérios foram excluídos. Dos 163 estudos encontrados através da frase de pesquisa, após critérios de inclusão, restaram 25 artigos, que foram lidos e 4 participaram do estudo.

\section{REVISÃO BIBLIOGRÁFICA}

Foi observado que apesar da utilização correta dos EPIs, o índice de contaminação dos otorrinolaringologistas, comparado aos demais profissionais da saúde, é maior (PADERNO A, et al., 2020). Entretanto, apesar da maior exposição aos procedimentos geradores de aerossóis, as taxas de infecção foram consideradas maiores em ambiente extra hospitalar, onde o uso de EPI é reduzido e os contatos são mais próximos e prolongados (PADERNO A, et al., 2020).

Outro impacto importante foi a redução de $84 \%$ das cirurgias funcionais, mantendo somente as relacionadas ao câncer, o que pode resultar em sobrecarga do sistema de saúde no período pós pandemia (SOWERBY LJ, et al., 2020). Além disso, deve-se levar em consideração o impacto emocional, destacando crescentes índices de ansiedade, depressão e angústia, bem como do medo de adoecer e de transmitir a doença para familiares (CIVANTOS AM, et al., 2020).

\section{CONSIDERAÇÕES FINAIS}


A maior vulnerabilidade dos profissionais da otorrinolaringologia ao coronavírus é minimizada pelo uso correto dos EPIs, assim, é de extrema importância incentivar a utilização adequada desses equipamentos. Além disso, o impacto da pandemia COVID 19 para os trabalhadores dessa área vai além do risco de contaminação, pois envolve também maiores índices de distúrbios psiquiátricos, como ansiedade e depressão.

\section{REFERÊNCIAS}

1. CIVANTOS AM, et al. Mental health among otolaryngology resident and attending physicians during the COVID-19 pandemic: National study. Head Neck, 2020; 42(7):1597-1609.

2. KUHAR HN, et al. Otolaryngology in the Time of Corona: Assessing Operative Impact and Risk During the COVID-19 Crisi. Otolaryngol Head Neck Surg, 2020; 163(2): 307-15.

3. PADERNO A, et al. SARS-CoV-2 Infection in Health Care Workers: Cross-sectional Analysis of an Otolaryngology Unit. Otolaryngology-Head and Neck Surgery 2020; 163(4): 671-672.

4. SOWERBY LJ, et al. International registry of otolaryngologist-head and neck surgeons with COVID-19. International Forum of Allergy \& Rhinology, 2020; 10(11). 
RESUMO SIMPLES: Revisão Bibliográfica

Título: Abordagem Terapêutica com Dupilumab em Pacientes com Rinossinusite Crônica Associada à Polipose Nasal

Autor/coautores: Fernanda Sotto Maior do Valle Pinheiro ${ }^{1}$, Luísa Furtado Bastos ${ }^{1}$, Luísa Marques Silva ${ }^{1}$, Maria Fernanda Souza de Castro ${ }^{1}$, Miguel Eduardo Guimarães Macedo¹.

Instituição: ${ }^{1}$ Faculdade de Ciências Médicas e da Saúde de Juiz de Fora (FCMS/JF), Juiz de Fora - MG.

Palavras-chave: Rinossinusite crônica, Polipose nasal, Dupilumab.

\section{INTRODUÇÃO}

Rinossinusite crônica (RSC) é uma doença inflamatória mediada, principalmente, por interleucinas 4 e 13. Sua prevalência ocidental é de $12 \%$, cursando com congestão nasal, diminuição/perda do olfato, secreção nasal anterior e/ou posterior. A RSC divide-se em sem/com polipose nasal (RSCsPN e RSCcPN, respectivamente), sendo que a presença dos pólipos gera grande impacto na qualidade de vida de seus portadores (BACHERT C, et al., 2020). Dupilumab é um anticorpo monoclonal dirigido ao receptor de IL-4a que inibe a sinalização de IL-4 e IL-13, citocinas relacionadas ao padrão inflamatório Th2, como ocorre na RSCcPN (BACHERT C, et al., 2019).

\section{OBJETIVO}

Analisar, através de uma revisão sistemática, a eficácia do tratamento com Dupilumab em pacientes com Rinossinusite Crônica com Polipose Nasal, avaliando seus efeitos benéficos nos principais sinais e sintomas da doença.

\section{MÉTODO}

Trata-se de uma revisão sistemática em que foram analisados, em dezembro de 2020, 4 artigos, que foram selecionados em sua totalidade, a partir dos critérios: Ensaios Clínicos Controlados e Randomizados, em inglês, dos últimos cinco anos, em humanos; tendo como referência a base de dados PubMed. A busca utilizou os descritores do MeSH: Chronic Rhinosinusitis; Nasal Polyps, Dupilumab.

\section{REVISÃO BIBLIOGRÁFICA}

Conforme estudo realizado com 60 pacientes, no grupo Dupilumab (vs placebo) houve melhora significativa na gravidade dos sintomas de sinusite e do olfato segundo o teste UPSIT $(P<0,05)$. A congestão nasal ou obstrução pela manhã e a rinorreia posterior pela manhã não apresentaram redução com significância ( $P=0,1220$ e $P=0,1650$, respectivamente) (JONSTAM K, et al., 2019).

Nos estudos SINUS-24 e SINUS-52, com 724 pacientes, o Dupilumab melhorou significativamente os desfechos coprimários $(p<0,0001)$. Nos pacientes com RSCcPN, reduziu-se o tamanho do pólipo, da opacificação dos seios da face, da gravidade dos sintomas e da anosmia, melhorando a qualidade de vida, sendo bem tolerado. Comparado com o grupo placebo, houve melhora da função pulmonar (avaliada com $\mathrm{FEV}_{1}$ ) e asma (avaliado com o questionário ACQ-6). Ademais, resultou na redução do uso de corticosteroides e do número de pacientes que precisaram de cirurgia nasossinusal (BACHERT C, et al., 2019).

\section{CONSIDERAÇÕES FINAIS}


O Dupilumab apresentou-se como um tratamento promissor, pois apresentou uma elevada eficácia nos principais sintomas da RSCcPN, como alterações do olfato e redução do tamanho dos pólipos nasais, melhorando a qualidade de vida dos pacientes. Entretanto, ainda são necessários outros estudos envolvendo uma população amostral maior a fim de avaliar possíveis riscos do uso desse anticorpo.

\section{REFERÊNCIAS}

1. BACHERT C, et al. Efficacy and safety of dupilumab in patients with severe chronic rhinosinusitis with nasal polyps (LIBERTY NP SINUS-24 and LIBERTY NP SINUS-52): results from two multicentre, randomised, double-blind, placebo-controlled, parallel-group phase 3 trials. Lancet, 2019; 394 (10209): 1638-50.

2. BACHERT C, et al. Dupilumab improves patient-reported outcomes in patients with chronic rhinosinusitis with nasal polyps and comorbid asthma. J Allergy Clin Immunol Pract, 2019; 7(7): 2447-9.

3. BACHERT C, et al. Dupilumab reduces opacification across all sinuses and related symptoms in patients with CRSwNP. Rhinology, 2020; 58(1): 10-7.

4. JONSTAM K, et al. Dupilumab reduces local type 2 pro-inflammatory biomarkers in chronic rhinosinusitis with nasal polyposis. Allergy, 2019; 74(4): 743-52. 
RESUMO SIMPLES: Revisão Bibliográfica

Título: Comparação entre a Eficácia do CPAP e do MAD no Tratamento Clínico da SAOS

Autor/coautores: Lucas Duarte Martins ${ }^{1}$, Luísa Furtado Bastos ${ }^{1}$, Luísa Marques Silva1, Miguel Eduardo Guimarães Macedo ${ }^{1}$, Saul Dresjan Camacho².

Instituição: ${ }^{1}$ Faculdade de Ciências Médicas e da Saúde de Juiz de Fora (FCMS/JF), Juiz de Fora - MG. 2Universidade do Grande Rio (UNIGRANRIO), Duque de Caxias - RJ.

Palavras-chave: Apneia Obstrutiva do Sono, Continuous positive airway pressure, Mandibular advancement device.

\section{INTRODUÇÃO}

Síndrome da Apneia Obstrutiva do Sono (SAOS) é uma doença crônica evolutiva que cursa com diminuição ou ausência do fluxo aéreo decorrente de obstruções das vias aéreas superiores (VAS). Tal condição resulta em diminuição de oxigênio e microdespertares do sono, tendo como consequências a sonolência diurna excessiva (SDE), a redução da qualidade de vida e o aumento do risco de doenças cardiovasculares (AARAB G, et al., 2017). Nesse cenário, os aparelhos de pressão positiva contínua das vias aéreas - CPAP - e o dispositivo de avanço mandibular - MAD - podem ser utilizados como opção de tratamento evitando a colapsibilidade da VAS (NIKOLOPOULOU M, et al., 2017).

\section{OBJETIVO}

Comparar, por meio de revisão sistemática, a eficácia do CPAP e do MAD na SAOS moderada/severa, analisando adesão e preferência do tratamento, sintomas subjetivos e parâmetros relacionados ao sono e ao aparelho cardiovascular.

\section{MÉTODO}

Trata-se de uma revisão sistemática em que foram analisados, no período de dezembro de 2020, os Ensaios Clínicos Controlados e Randomizados publicados em inglês, dos últimos cinco anos, em humanos; tendo como referência a base de dados National Library of Medicine (MEDLINE). A busca fundamentou-se em consulta ao MeSH, utilizando os descritores: Obstructive Sleep Apnea; Continuous Positive Airway Pressure; Mandibular Advancement Device.

\section{REVISÃO BIBLIOGRÁFICA}

Um estudo realizado com 118 pacientes selecionados, com apenas 54 prosseguindo até o final do estudo, após 12 meses de acompanhamento de polissonografias do sono em dois grupos (CPAP e MAD), foi observada uma redução significativa de índice de apneia-hipopneia (IAH) em ambos os grupos. A redução do IAH foi maior no CPAP quando comparado ao MAD (DE VRIES GE, et al., 2020).

Em outro estudo com 40 participantes, todos os parâmetros relacionados ao sono, como a saturação do oxigênio no sangue mínimo e médio, foram significativamente melhorados por ambas terapias. Além disso, em questão de adaptação e conforto, os pacientes preferiram utilizar o MAD ao CPAP, relatando uma melhora da qualidade de vida. Entretanto, os parâmetros cardiovasculares, como a pressão arterial e dilatação mediada por fluxo não mostraram alterações significativas após uso dos dispositivos (YAMAMOTO U, et al., 2019).

\section{CONSIDERAÇÕES FINAIS}


MAD e CPAP mostraram eficácias semelhantes na melhora dos sintomas subjetivos e parâmetros relacionados à SAOS moderada/levemente grave. Assim, MAD torna-se uma opção de tratamento alternativo para CPAP, especialmente para a melhora dos sintomas subjetivos e de qualidade de vida em pacientes com recusa ao CPAP. Entretanto, são necessários outros estudos para avaliar parâmetros cardiovasculares.

\section{REFERÊNCIAS}

1. AARAB G, et al. Oral appliance therapy versus nasal continuous positive airway pressure in obstructive sleep apnea: a randomized, placebo-controlled trial on psychological distress. Clin Oral Investig, 2017; 21(7): 2371-8.

2. NIKOLOPOULOU M, et al. Oral appliance therapy versus nasal continuous positive airway pressure in obstructive sleep apnoea syndrome: a randomised, placebo-controlled trial on self-reported symptoms of common sleep disorders and sleep-related problems. J Oral Rehabil, 2017; 44(6): 452-60.

3. DE VRIES GE, et al. Clinical- and Cost-Effectiveness of a Mandibular Advancement Device Versus Continuous Positive Airway Pressure in Moderate Obstructive Sleep Apnea. J Clin Sleep Med, 2019; 15(10): 1477-85.

4. YAMAMOTO $U$, et al. Crossover comparison between CPAP and mandibular advancement device with adherence monitor about the effects on endothelial function, blood pressure and symptoms in patients with obstructive sleep apnea. Heart Vessels, 2019; 34(10): 1692-702. 
RESUMO SIMPLES: Revisão Bibliográfica

Título: Eficácia da Faringoplastia Lateral como Modalidade Terapêutica da Síndrome de Apneia Obstrutiva do Sono

Autor/coautores: Milla Giancristofaro Dutra, Bernardo Valle Zanetti, Daniel Camargo de Andrade, Maurício Silva de Moraes Souza, Miguel Eduardo Guimarães Macedo.

Instituição: Faculdade de Ciências Médicas e da Saúde de Juiz de Fora (FCMS/JF), Juiz de Fora - MG.

Palavras-chave: Faringoplastia Lateral, Síndrome de Apneia Obstrutiva do Sono, Tratamento.

\section{INTRODUÇÃO}

A síndrome de apneia obstrutiva do sono (SAOS) é resultante de episódios de colapsos parciais ou totais de estruturas das vias aéreas superiores, principalmente da parede lateral da faringe (PLF) (PINTO JA, et al., 2020). Apesar da existência de modalidades terapêuticas convencionais, nota-se que a estabilização do quadro não é atingida em número considerável de pacientes (PARK D, et al., 2018). Dessa forma, torna-se imprescindível analisar a eficácia de procedimentos cirúrgicos como a faringoplastia lateral (FL), abordagem transoral consistente em microdissecações no constritor faríngeo superior (CAMMAROTO G, et al., 2020).

\section{OBJETIVO}

Investigar o possível estado da arte sobre a eficácia da FL como modalidade cirúrgica para o tratamento da SAOS em pacientes que não obtiveram estabilização das vias aéreas com terapias convencionais.

\section{MÉTODO}

Durante dezembro de 2020 realizou-se uma revisão sistemática através de busca na base de dados MedLine, utilizando descritores "Lateral Pharyngoplasty"; "Obstructive Sleep Apnea"; "Treatment"; e variações obtidas no MeSH. Foram incluídos Estudos de Caso e Ensaios Clínicos Controlados e Randomizados; todos realizados em humanos, nos últimos cinco anos e em inglês. Foram excluídos estudos não relacionados diretamente com o tema e aqueles cujos grupos amostrais não tentaram terapias convencionais.

\section{REVISÃO BIBLIOGRÁFICA}

Foram encontrados 29 artigos, sendo quatro deles utilizados na confecção deste trabalho. Um estudo mostrou queda estatisticamente significante do índice apnéia-hipopnéia (IAH) nos 20 pacientes analisados com diminuição da mediana de 41,2 para 9,5 ( $P=0,009)$-, bem como aumento de $82,6 \pm 10,3$ para 86,9 $\pm 11,1$ na saturação mínima de oxigênio ( $P=0,007$ ) (CAMMOROTO $G$, et al., 2020).

Embora 10\% tenha desenvolvido distúrbios de deglutição ou refluxo oronasal, estes desapareceram em até 14,5 dias após a cirurgia (CAMMOROTO G, et al., 2020). Ademais, evidenciou-se redução dos microdespertares em 38 pacientes investigados (19,5 $\pm 22,6$ por hora versus $11,0 \pm 13,4 ; p=0,001)$, resultando em aumento dos estágios 3 e 4 do sono REM (PINTO JA, et al., 2020). Outrossim, notou-se melhora nos valores da polissonografia e Escala de Sonolência de Epworth em 23 pacientes observados, comprovando redução da sonolência diurna e aumento da qualidade de vida (DIZDAR D, et al., 2015).

\section{CONSIDERAÇÕES FINAIS}


A faringoplastia lateral mostrou-se uma abordagem segura e eficaz, visto que provocou os resultados desejados nos pacientes com síndrome de apneia obstrutiva do sono, sendo capaz de provocar o alargamento orofaríngeo e o enrijecimento fibromuscular necessários para melhora do quadro.

\section{REFERÊNCIAS}

1. CAMMAROTO G, et al. Manipulation of lateral pharyngeal wall muscles in sleep surgery: a review of the literature. International Journal of Environmental Research and Public Health, 2020; 17(15): 5315.

2. DIZDAR D, et al. Comparative analysis of lateral pharyngoplasty and uvulopalatopharyngoplasty techniques with polisomnography and epworth sleepiness scales. The Journal of Craniofacial Surgery, 2015; 26(7): e647-51.

3. PARK D, et al. Surgical outcomes of overlapping lateral pharyngoplasty with or without coblator tongue base resection for obstructive sleep apnea. European Archives of Oto-Rhino-Laryngology, 2018; 275(5): 1189-96.

4. PINTO JA, et al. Lateral-expansion pharyngoplasty: combined technique for the treatment of obstructive sleep apnea syndrome. International Archives of Otorhinolaryngology, 2020; 24(1): e107-11. 
RESUMO SIMPLES: Revisão Bibliográfica

Título: Análise do Tratamento com Laser na Papilomatose Laríngea Recorrente

Autor/coautores: Breno Veggi Godinho¹, Miguel Eduardo Guimarães Macedo², Olívia Féres Varela³, Laura Ribeiro Galhardo Brun ${ }^{3}$, Renato Cabral Pentagna1.

Instituição: ${ }^{1}$ Faculdade de Medicina da Faculdade de Ciências Médicas e da Saúde de Juiz de Fora (FCMS/JF), Juiz de Fora - MG; ${ }^{2}$ Médico Otorrinolaringologista pela Universidade Federal de Juiz de Fora (UFJF), Juiz De Fora - MG; ${ }^{3}$ Faculdade de Medicina do Centro Universitário Presidente Antônio Carlos (UNIPAC), Juiz de Fora - MG.

Palavras-chave: Laser, Papilomatose laríngea recorrente, Cirurgia.

\section{INTRODUÇÃO}

A papilomatose respiratória recorrente (PRR) é uma doença causada pelo papilomavírus humano (HPV) que acomete, principalmente, a laringe (BOWLES PF, et al., 2019). Caracterizada por lesões verrucosas de vias aéreas superiores (RASMUSSEN ER, et al., 2017), pode cursar com obstrução, disfonia e estridor (BOWLES PF, et al., 2019). Em crianças, afeta especialmente cordas vocais e, em adultos, regiões supra e infraglóticas e traqueia (PAPASPYROU G, et al., 2016). A maioria dos pacientes realiza múltiplas cirurgias ao longo da vida (DODHIA S, et al., 2017). Os tratamentos incluem ressecção com microdebridador e vaporização a laser (BOWLES PF, et al., 2019).

\section{OBJETIVO}

Realizar, através de revisão de literatura, uma análise das vantagens e desvantagens, tanto para o paciente quanto para o profissional de saúde, do tratamento com laser na papilomatose laríngea recorrente.

\section{MÉTODO}

Revisão sistemática que analisou, em dezembro de 2020, estudos em humanos, publicados nos últimos 5 anos, em inglês, na base de dados National Library of Medicine (MEDLINE). A busca pelos descritores utilizados ocorreu mediante consulta ao Medical Subject Headings (MeSH), sendo eles: "laser", "recurrent laryngeal papillomatosis". Foram encontrados 4 estudos e todos foram incluídos no escopo da revisão, pois versam diretamente sobre a temática.

\section{REVISÃO BIBLIOGRÁFICA}

Um estudo constatou que dentre 45 pacientes tratados com laser, nenhum apresentou complicação vital, mas observou-se sinéquia de comissura anterior $(n=2)$, formação de camada fibrótica em glote $(n=3)$ e que o alto custo do equipamento, os riscos de dano tecidual e lesões a laser ao cirurgião são desvantagens do laser de CO2 (PAPASPYROU G, et al., 2016).

Outro trabalho descreveu uma variação técnica no uso do laser de $\mathrm{CO} 2$ ("ablation suction"). Aplicada em 29 pacientes, 59\% não tiveram recidiva ou tiveram apenas recorrência assintomática, dispensando outras cirurgias. Acredita-se em redução do risco de trauma na mucosa das pregas vocais e lâmina própria superficial, promovendo bons resultados na voz (BOWLES PF, et al., 2019).

Ademais, outro estudo mostrou que, num grupo de 30 adultos tratados para PRR, o laser de CO2 foi mais utilizado (32 vezes), seguido pelo microdebridador (15 vezes). Porém, nenhuma diferença 
estatisticamente significativa foi observada na correlação entre o tempo para recorrência e método cirúrgico (RASMUSSEN ER, et al., 2017).

\section{CONSIDERAÇÕES FINAIS}

Apesar de não haver cura para PRR, o tratamento com laser surge como procedimento inovador que auxilia na regressão da doença. Contudo, são necessários novos estudos e aprimoramento de novas técnicas para diminuir número de recidivas e complicações.

\section{REFERÊNCIAS}

1. BOWLES PF, et al. CO 2 laser "Ablation Suction" technique for treatment of laryngeal recurrent respiratory papillomatosis. Clinical Otolaryngology, 2019; 44(5): 884-885.

2. DODHIA S, et al. Investigation of the Presence of HPV on KTP Laser Fibers Following KTP Laser Treatment of Papilloma. The Laryngoscope, 2017; 128(4): 926-928.

3. PAPASPYROU G, et al. Retrospective analysis of laser versus other therapeutic modalities for laryngeal papillomatosis: European multicenter study. J BUON, 2016; 21(5): 1274-1278.

4. RASMUSSEN ER, et al. Long-term follow-up and outcome in patients with recurrent respiratory laryngeal papillomatosis. Danish Medical Journal, 2017; 64(12): A5424. 
RESUMO SIMPLES: Revisão Bibliográfica

Título: Efeitos do Treinamento dos Músculos Respiratórios no Tratamento da Apneia Obstrutiva do Sono: Uma Revisão Sistemática

Autor/coautores: Amanda Márcia de Lima Resende ${ }^{1}$, Lorhainy Suellen Costa ${ }^{1}$, Mariana Vanon Moreira ${ }^{1}$, Raul Ciotti Abreu², Miguel Eduardo Guimarães Macedo'.

Instituição: ${ }^{1}$ Faculdade de Ciências Médicas e da Saúde de Juiz de Fora (FCMS/JF), Juiz de Fora - MG; ${ }^{2}$ Universidade Federal de Juiz de Fora (UFJF), Juiz de Fora - MG.

Palavras-chave: Síndrome da Apneia Obstrutiva do Sono, Exercícios.

\section{INTRODUÇÃO}

Síndrome da Apneia Obstrutiva do Sono (SAOS) é um distúrbio prevalente na população, caracterizado pela oclusão parcial (hipopneia) ou completa (apneia) das vias aéreas superiores. Episódios de hipóxia/reoxigenação que ocorrem durante 0 sono podem levar ao agravamento de doenças cardiovasculares, além de consequências sistêmicas (SOUZA AKF, et al., 2017). As opções terapêuticas para a SAOS são limitadas na prática clínica, sendo o Continuous Positive Airway Pressure (CPAP) e o tratamento cirúrgico amplamentes prescritos. Entretanto, ambos são caros, invasivos e podem causar desconforto aos pacientes, obtendo uma baixa adesão (KUO Y, et al., 2017). Assim, é imprescindível maior investigação sobre tratamentos alternativos, como o treinamento muscular das vias aéreas superiores.

\section{OBJETIVO}

Analisar as implicações clínicas do treinamento de músculos respiratórios no tratamento de pacientes que possuem a Síndrome da Apneia Obstrutiva do Sono (SAOS) por meio de uma revisão sistemática da literatura.

\section{MÉTODO}

Trata-se de uma revisão sistemática. Foram realizadas pesquisas na base de dados National Library Of Medicine (MedLine) em novembro de 2020, utilizando os descritores "obstructive sleep apnea", "exercise" e variações no MeSH. Inicialmente, obtiveram-se 586 artigos. Utilizando os critérios de inclusão: ensaios clínicos controlados randomizados, em humanos, inglês, dos últimos 5 anos, encontraram-se 24 artigos. Por não estarem diretamente relacionados ao tema, 20 foram excluídos. Assim, 4 artigos foram selecionados.

\section{REVISÃO BIBLIOGRÁFICA}

Dos 24 estudos encontrados, selecionaram-se 4, porque preencheram os critérios de seleção. Os ensaios envolveram 105 pacientes adultos, sendo $58 \%$ do sexo masculino. Analiasaram-se alguns índices: Escala de sonolência de Epworth (ESE), Índice de Qualidade do Sono de Pittsburgh (PSQI), Índice de Apneiahipoapneia (IAH). 75\% dos ensaios relataram que o treinamento muscular resultou na melhora da pontuação dos pacientes no PSQI (SOUZA AKF, et al., 2017; VRANISH JR e BAILEY EF, 2016; KUO Y, et al., 2017).

Os outros $25 \%$ indicaram aumento relevante da saturação de oxigênio dos pacientes durante o sono (NEUMANNOVA K, et al., 2018). Em relação à ESE, não foram encontradas alterações significativas pelos estudos que a analisaram. Dois ensaios investigaram o IAH. Em um deles, houve melhora da apneia (KUO Y, et al., 2017). No outro, não foi obtida nenhuma difrença significativa (NEUMANNOVA K, et al., 2018).

\section{CONSIDERAÇÕES FINAIS}


O treinamento dos músculos respiratórios é eficaz como um tratamento complementar ao CPAP e à cirurgia, haja vista que demonstrou aumento efetivo na qualidade do sono. Dessa forma, houve a melhora no prognóstico e na qualidade de vida dos pacientes com SAOS.

\section{REFERÊNCIAS}

1. VRANISH JR, BAILEY EF. Inspiratory muscle training improves sleep and mitigates cardiovascular dysfunction in obstructive sleep apnea. SLEEP, 2016; 39(6): 1179-85.

2. SOUZA AKF, et al. Effectiveness of inspiratory muscle training on sleep and functional capacity to exercise in obstructive sleep apnea: a randomized controlled trial. Sleep and Breathing, 2018; 22(3): 631-9.

3. NEUMANNOVA K, et al. Pulmonary rehabilitation and oropharyngeal exercises as an adjunct therapy in obstructive sleep apnea: a randomized controlled trial. Sleep Medicine, 2018; 52: 92-7.

4. KUO Y, et al. Short-term expiratory muscle strength training attenuates sleep apnea and improves sleep quality in patients with obstructive sleep apnea. Respiratory Physiology and Neurobiology, 2017; 243: 8691. 
RESUMO SIMPLES: Revisão Bibliográfica

Título: A relação do desvio de septo com a rinossinusite crônica e com a gravidade dos sintomas de obstrução nasal

Autor/coautores: Laura Ribeiro Galhardo Brun ${ }^{1}$, Miguel Eduardo Guimarães Macedo², Olívia Féres Varela1, Breno Veggi Godinho³, Renato Cabral Pentagna ${ }^{3}$.

Instituição: ${ }^{1}$ Acadêmica de Medicina do Centro Universitário Presidente Antônio Carlos (UNIPAC), Juiz de Fora - MG; ${ }^{2}$ Médico Otorrinolaringologista pela Universidade Federal de Juiz de Fora (UFJF), Juiz de Fora MG; ${ }^{3}$ Acadêmico de Medicina da Faculdade de Ciências Médicas e da Saúde (FCMS/JF), Juiz de Fora - MG.

Palavras-chave: Deviated nasal septum, Chronic rhinosinusitis, Nasal obstruction.

\section{INTRODUÇÃO}

A rinossinusite crônica (RSC) é uma doença frequente, que afeta a qualidade de vida (QV). Sua fisiopatologia pode ser predisposta por variações anatômicas, como o desvio de septo nasal (DSN) (MADANI AS, et al., 2015). A prevalência de DSN é alta em pacientes com RSC e sintomas de ON. (JANOVIC N, et al., 2020). A questão é analisar se o DSN está realmente envolvido nesse processo, e revisar a sua contribuição no agravamento dos sintomas de ON. A importância do tema é clara, pois quando demonstradas tais relações, a septoplastia se consolida como possibilidade terapêutica para melhora da QV.

\section{OBJETIVO}

Relacionar o DSN com rinossinusite crônica e sintomas ON, a fim de concluir se o DSN pode ser considerado fator causal e/ou de pior prognóstico, elucidando seu grau de contribuição e prevalência.

\section{MÉTODO}

Revisão sistemática concluída após busca realizada entre Outubro e Dezembro de 2020 nas bases de dados Scielo, MedLine e Pubmed, usando os descritores "deviated nasal septum", "chronic rhinosinusitis", e "nasal obstruction". Encontrados 56 artigos e selecionados 5, pelos resultados mais relevantes. Critérios de inclusão: artigos originais, publicados nos últimos 5 anos. Critérios de exclusão: artigos não originais e/ou que apresentavam divergências entre si quanto ao objetivo do estudo.

\section{REVISÃO BIBLIOGRÁFICA}

Em estudo feito com 60 pacientes com RSC, o DSN foi encontrado em 49 (81,7\%) indivíduos. (MADANI AS, et al., 2015). Em outro estudo com 386 pacientes com ON submetidos à tomografia computadorizada, a prevalência de DSN foi de $92,7 \%$. (JANOVIC N, et al., 2020). Na presente metanálise, observou-se em um estudo transversal com 98 participantes com RSC associação significativa entre a gravidade do DSN e os sintomas de ON ( $p=0,025$ ) (LAZIM NM, et al., 2019), e que o DSN é fator de risco para RSC com pólipos nasais, sem ser possível definir se é fator de risco para RSC sem pólipos (AHN JC, et al., 2016).

Uma avaliação de 150 pacientes com ON e DSN mostrou que as deformidades do septo nasal anterior estão fortemente associadas à má resposta ao tratamento médico, maior gravidade da RSC e maior gravidade de ON (SANCHEZ FM, et al., 2017).

\section{CONSIDERAÇÕES FINAIS}


O DSN é encontrado na maioria dos pacientes com RSC e está fortemente ligado à gravidade dos sintomas de ON e pior resposta ao tratamento clínico. O DSN em pacientes com RSC e ON merece atenção, para que a septoplastia seja considerada como opção terapêutica.

\section{REFERÊNCIAS:}

1. AHN JC, et al. Prevalence and Risk Factors of Chronic Rhinosinusitus, Allergic Rhinitis and Nasal Septal Deviation: Results os the Korean National Health and Nutrition Survery 2008-2012. JAMA Otolaryngology Head and Neck Sugery. Feb 2016; 142(2):162-7

2. JANOVIC N, et al. Relationship between nasal septum morphology and nasal obstruction symptom severity: computed tomography study. Brazilian Journal Of Otorhinolaryngology. Oct 2020; S1808-8694 (20) 30157-9

3. LAZIM NM, et al. Significance of Nasal Septum Angulation and Its Association with Rhinosinusitis Symptom Scores. Medeniyet Medical Journal, Dec 2019; 34(4): 333-339

4. MADANI AS, et al. The incidence of nasal septal deviation and its relation with chronic rhinosinusitis in patients undergoing functional endoscopic sinus surgery. The Journal of The Pakistan Medical Association, Jun 2015; 65(6): 612-4.

5. SANCHEZ FM, et al. Influence of nasal septum deformity on nasal obstruction, disease severity, and medical treatment response among children and adolescents with persistent allergic rhinitis. International Journal of Pediatric Otorhinolaringology, Apr 2017; 95:145-154. 
RESUMO SIMPLES: Revisão Bibliográfica

Título: Uso de Mamadeira Como Fator De Risco Para Otite Média Aguda Em Lactentes

Autor/coautores: Amanda Schmitberger Pelisson¹, Gabriela Araujo Costa1, Luisa Argolo Assis², Maria Paula Tecles Brandão Vargas ${ }^{3}$.

Instituição: ${ }^{1}$ Centro Universitário de Belo Horizonte (UniBH), Belo horizonte - MG; ${ }^{2}$ Pontifícia Universidade Católica (PUC), Betim - MG; ${ }^{3}$ Faculdade de Ciências Médicas e da Saúde de Juiz de Fora (FCMS/JF), Juiz de Fora - MG.

Palavras-chave: Otite média, Aleitamento materno, Mamadeiras.

\section{INTRODUÇÃO}

Otite média aguda (OMA) é uma inflamação da mucosa que reveste a orelha média e acomete frequentemente crianças menores de três anos. Apesar do aleitamento materno ser um importante fator de proteção para a doença, atualmente mais da metade dos lactentes fazem uso de mamadeira como substituta ou complementar à amamentação (BOONE KN, et al., 2016). Assim, a incidência de OMA nessa faixa etária vem aumentando nos últimos anos, evidenciando que o uso da mamadeira é fator de risco importante na gênese da doença devido à diferença entre a fisiologia dos tipos de sucção (NADAL LF, et al., 2017).

\section{OBJETIVO}

Comparar a fisiologia da sucção do aleitamento materno exclusivo e do aleitamento com uso de mamadeira e seu papel como fator de risco na ocorrência de otite média aguda em lactentes.

\section{MÉTODO}

Revisão integrativa com estudos dos bancos de dados PUBMED, BVS e Scielo. Foram utilizados os descritores "Otite média", "Aleitamento Materno" e "Mamadeiras", suas traduções em inglês e variações, publicados nos últimos 5 anos. Foram encontrados sete artigos dos quais quatro foram excluídos por abordarem a posição da cabeça do lactente e não a fisiologia da sucção, sendo três selecionados para a execução deste trabalho.

\section{REVISÃO BIBLIOGRÁFICA}

Em relação às diferenças da fisiologia das sucções, no aleitamento materno ocorre anteriorização e abaixamento da região anterior do palato mole durante a deglutição e elevação da sua parte vertical, garantindo fechamento da orofaringe e impossibilitando a entrada do leite pela tuba auditiva. Em contrapartida, com o uso da mamadeira, existe uma menor resistência na sucção e a contração muscular é menos intensa, com consequente flacidez e hipofunção do músculo tensor do palato mole, responsável pela abertura da tuba auditiva (SIQUEIRA FC e PINHEIRO AR, 2020).

Assim, há maior facilidade de entrada do leite pela orofaringe, podendo atingir a tuba auditiva e causar proliferação microbiana, resultando na OMA (NADAL LF, et al., 2017). Essa vantagem do aleitamento materno merece especial atenção pelos profissionais de saúde e sua explicação à família da criança, de forma compreensível, deve ser adicionada ao arsenal de vantagens da amamentação exclusiva ao seio materno, de forma a estimular essa prática (BRASIL, 2015).

\section{CONSIDERAÇÕES FINAIS}


Para a prevenção da OMA em lactentes, seja como primeiro episódio ou recorrência, deve-se evitar ao máximo o uso de mamadeira e priorizar a manutenção do aleitamento materno exclusivo ao seio materno até os 6 meses de vida da criança.

\section{REFERÊNCIAS}

1. BOONE KN, et al. Feeding at the Breast and Expressed Milk Feeding: Associations with Otitis Media and Diarrhea in Infants. The journal of pediatrics. 2016. Julho; 174:118-125. Disponível em: https://pubmed.ncbi.nlm.nih.gov/27174145/. Acessado em: 08/12/2020.

2. BRASIL Ministério da Saúde, Secretaria de Atenção à Saúde, Departamento de Atenção Básica. Saúde da criança: aleitamento materno e alimentação complementar. 2nd ed. Brasília: Ministério da Saúde; 2015. Disponível em:

http://bvsms.saude.gov.br/bvs/publicacoes/aleitamento_materno_alimentacao_complementar_2edicao.p df. Acessado em: 13/12/2020.

3. NADAL LF, et al. Investigação das práticas maternas sobre aleitamento materno e sua relação com a infecção de vias aéreas superiores e otite média Rev. CEFAC. 2017 Maio-Jun; 19(3):387-394. Disponível em: $\quad$ https://www.scielo.br/scielo.php?pid=S1516-18462017000300387\&script=sci_abstract\&tlng=pt. Acessado em: 08/12/2020.

4. SIQUEIRA FC, PINHEIRO AR. Incentivo ao aleitamento materno exclusivo até o sexto mês em uma unidade básica de saúde do Piauí. Uma Sus, 2020. Disponível em: https://ares.unasus.gov.br/acervo/handle/ARES/18962. Acessado em: 08/12/2020. 
RESUMO SIMPLES: Revisão Bibliográfica

Título: Avaliação de questionários para mensuração da qualidade de vida relacionada à saúde em pacientes com desordens na deglutição: uma revisão sistemática

Autor/coautores: Isadora Soares Lopes ${ }^{1}$, Maria Paula Ribeiro Dantas Bezerra ${ }^{1}$, Larissa Melo Silva1 ${ }^{1}$, Mônica Claudino Medeiros Honorato², Lidiane Maria De Brito Macedo Ferreira ${ }^{3}$.

Instituição: ${ }^{1}$ Acadêmica de Medicina da Universidade Federal do Rio Grande do Norte (UFRN), Natal - RN; ${ }^{2}$ Residente em Otorrinolaringologia no Hospital Universitário Onofre Lopes (HUOL), Natal - RN; ${ }^{3}$ Professora do Departamento de Cirurgia da UFRN, Natal - RN.

Palavras-chave: Transtornos de deglutição, Qualidade de vida, Endoscopia.

\section{INTRODUÇÃO}

A disfagia orofaríngea (DO) é caracterizada pela disfunção na deglutição de diferentes etiologias, dentre alterações funcionais e estruturais (ROMMEL N e HAMDY S, 2016). Essa condição acarreta complicações graves, como má nutrição, desidratação e aspiração, podendo evoluir para pneumonias aspirativas. Ademais, a disfagia agrega severo impacto psicossocial e reduzida qualidade de vida (JONES E, et al., 2018). Assim, a utilização de ferramentas, como questionários, para avaliar objetivamente a correlação entre DO e qualidade de vida relacionada à saúde é necessária para adequado plano terapêutico desses pacientes.

\section{OBJETIVO}

Avaliar instrumentos disponíveis para análise e quantificação objetiva do impacto na qualidade de vida de pacientes com desordens da deglutição, além de descrever ferramentas validadas para avaliar disfagia.

\section{MÉTODOS}

Realizou-se busca sistemática nas bases de dados MEDLINE, SciELO e PubMed, com os descritores "deglutition disorders" e "quality adjusted life years" ou "sickness impact profile" ou "indicators of quality of life" nos últimos 10 anos. Cada artigo foi avaliado para elegibilidade independentemente por duas pesquisadoras, considerando título e resumo, para posterior leitura completa. Discordâncias foram resolvidas por terceira pesquisadora. Os critérios de inclusão: abordar disfagia orofaríngea; correlacionar DO com seu impacto na qualidade de vida; avaliar qualidade de vida com instrumentos objetivos.

\section{REVISÃO BIBLIOGRÁFICA}

Foram encontrados 335 estudos, 15 selecionados para leitura completa e 12 incluídos na análise final. As evidências revelaram diversas ferramentas para avaliar o impacto da disfagia em qualidade de vida, que, em sua maioria, não estão devidamente validadas ou apresentam uso sustentado por estudos de baixa qualidade metodológica e tornam-se pouco confiáveis.

Certos questionários foram elaborados adequadamente para populações específicas, como o Hospital for Special Surgery Dysphagia and Dysphonia Inventory (HSS-DDI) para pós-operatório de cirurgia cervical, mas carecem de validação em coorte externa (HUGHES AP, et al., 2018).

Destaca-se ainda o questionário Swallowing-Quality of Life (SWAL-QOL), principal ferramenta analisada, mas cuja eficiência é contestada por novos estudos (CORDIER R, et al., 2018); e o Dysphagia Handicap Index (DHI), com abrangente aplicação em distúrbios da deglutição (SILGERBLEIT, AK, et al., 2012). Em suma, destaca-se ausência de instrumento padronizado para esta condição e ferramentas validadas para populações específicas, mas baixa acurácia para outros quadros. 


\section{CONSIDERAÇÕES FINAIS}

A associação entre disfagia orofaríngea e qualidade de vida relacionada à saúde não deve ser negligenciada no plano terapêutico. Embora existam questionários úteis nessa avaliação, novos estudos são necessários para melhor compreensão dessa correlação, visando elaborar ferramentas objetivas, acuradas e confiáveis, com desenhos metodologicamente adequados.

\section{REFERÊNCIAS}

1. CORDIER R, et al. Using Rasch Analysis to Evaluate the Reliability and Validity of the Swallowing Quality of Life Questionnaire: An Item Response Theory Approach. Dysphagia, 2018; 33, 441-456.

2. HUGHES AP, et al. HSS Dysphagia and Dysphonia Inventory (HSS-DDI) Following Anterior Cervical Fusion: Patient-Derived, Validated, Condition-Specific Patient-Reported Outcome Measure Outperforms Existing Indices. J Bone Joint Surg Am. 2018 May 16; 100(10): e66.

3. JONES E, et al. Health-Related Quality of Life and Oropharyngeal Dysphagia: A Systematic Review. Dysphagia, 2018; 33, 141-172.

4. ROMMEL N, HAMDY S. Oropharyngeal dysphagia: manifestations and diagnosis. Nat Rev Gastroenterol Hepatol, 2016; 13, 49-59.

5. SILBERGLEIT AK, et al. The Dysphagia Handicap Index: Development and Validation. Dysphagia, 2012; $27,46-52$. 
RESUMO SIMPLES: Revisão Bibliográfica

Título: Os impactos da septoplastia para alívio da obstrução nasal

Autor/coautores: Ana Carolina Alves Meneses, Isabella Soares de Freitas, Márcio Rabelo Mota.

Instituição: Centro Universitário de Brasília (UniCeub), Brasília - DF.

Palavras-chave: Cirurgias funcionais nasais, Obstrução nasal, Qualidade de vida.

\section{INTRODUÇÃO}

A septoplastia é considerada uma das cirurgias funcionais nasais mais comuns na área da otorrinolaringologia. A indicação mais discutida para esse tipo de procedimento é a obstrução nasal, visto que pode acarretar prejuízos à funcionalidade do nariz (JÚNIOR J, et al., 2019). Dessa maneira, mediante alteração fisiológica do referido órgão, a qualidade de vida do paciente declina, caso não reaja ao tratamento clínico com uso de corticóides tópicos ou anti-histamínicos, por exemplo. Nessa perspectiva, a cirurgia tornase válida, visando, dentre outros aspectos, garantir bem-estar, por meio da restauração do fluxo respiratório normal do paciente (RESENDE L, et al., 2018).

\section{OBJETIVO}

Revisar a literatura científica acerca dos impactos da septoplastia como método cirúrgico funcional nasal gerador de melhorias para qualidade de vida do paciente, analisando alívio da obstrução nasal acarretado, pontuando-se a retomada da funcionalidade do nariz.

\section{REVISÃO BIBLIOGRÁFICA}

A septoplastia é uma cirurgia funcional nasal importante para pacientes com queixas como obstrução nasal, roncos noturnos e quadros referentes ao desvio septal (JÚNIOR J, et al., 2019). No que tange à obstrução nasal, umas das indicações para o procedimento cirúrgico, verifica-se que, caso o paciente não reaja a mecanismos clínicos de tratamentos anteriores, a cirurgia revela-se um instrumento promissor para melhora da qualidade de vida destes indivíduos (MACHADO AM, et al., 2017).

Nessa perspectiva, dentre os impactos gerados pela septoplastia, destacam-se a melhora no padrão respiratório do paciente, bem como a retomada da funcionalidade nasal. Isso porque, mediante correção do desvio septal, sendo este ósseo, cartilaginoso ou misto, observa-se recuperação da permeabilidade das vias aéreas superiores, havendo, assim, mitigação do grau de obstrução (JÚNIOR J, et al., 2019).

Por fim, o procedimento se mostra eficaz de forma precoce no pós-operatório, posto que métodos avaliativos evidenciam melhoras geradoras de bem-estar e conforto ao paciente (RESENDE L, et al., 2018).

\section{CONSIDERAÇÕES FINAIS}

A partir da análise dos dados, conclui-se que, a septoplastia apresenta-se como um mecanismo promissor para alívio da obstrução nasal, concedendo impactos positivos à qualidade de vida dos pacientes. Por meio da correção septal, o fluxo de ar pelas vias aéreas superiores melhora, proporcionando correta funcionalidade nasal. Assim, o referido procedimento cirúrgico demonstra-se eficaz nos casos em que métodos clínicos de tratamento não foram suficientemente benéficos.

\section{REFERÊNCIAS}


1. JÚNIOR J, et al. Comparação entre métodos subjetivos e objetivo para avaliação de pacientes. submetidos a cirurgias funcionais nasais. Revista da Faculdade de Ciências Médicas de Sorocaba. 2019; 21(3): 114 119.

2. MACHADO AM, et al. Revisão bibliográfica e planejamento de protocolo através de questionário sinonasal outcome test, rinometria e tomografia computadorizada em doentes propostos para septoplastia. Revista Portuguesa de Otorrinolaringologia e Cirurgia de Cabeça e Pescoço, 2017; 55(4): e384.

3. RESENDE L, et al. Qualidade de vida específica da doença após septoplastia e fratura bilateral de concha inferior em pacientes com obstrução nasal. Brazilian Journal of Otorhinolaryngology, 2018; 84(5): 591-598. 
RESUMO SIMPLES: Revisão Bibliográfica

Título: Fatores prognósticos em Otite Média Aguda: uma Revisão Sistemática

Autor/coautores: Gianluca Carvalho Quinet de Andrade ${ }^{1}$, Leonardo Ramos Ribeiro de Oliveira ${ }^{2}$, Marina Tambasco Freire Vicente ${ }^{1}$, Pedro Veiga de Paula Soares ${ }^{1}$.

Instituições: ${ }^{1}$ Faculdade de Ciências Médicas e da Saúde de Juiz de Fora (FCMS/JF), Juiz de Fora - MG; ${ }^{2}$ Hospital Evandro Ribeiro, Juiz de Fora - MG.

Palavras-chave: Fatores prognósticos, Otite Média Aguda, Otorrinolaringologia.

\section{INTRODUÇÃO}

A Otite Média Aguda (OMA) é uma infecção de Ouvido Médio causada por vírus ou bactérias. A OMA é uma das infecções bacterianas mais comuns em crianças de até cinco anos de idade, além de ser a principal indicação para tratamento com antimicrobianos em cenário ambulatorial (TAHTINEN PA, et al., 2017). Embora os antibióticos encurtem os sintomas e a duração da efusão do ouvido médio, é importante pesar seus benefícios e malefícios na OM (SHIELDER AGM, et al., 2017). Os fatores prognósticos para falha do tratamento permanecem incertos (TAHTINEN PA, et al., 2017).

\section{OBJETIVO}

Analisar, por meio de uma revisão sistemática, a literatura científica que tange os fatores prognósticos relacionados diretamente à terapia antimicrobiana adotada em pacientes com quadro clínico de Otite Média Aguda.

\section{MÉTODO}

Foram analisados 3 artigos, através de uma revisão sistemática, em dezembro de 2020, que foram selecionados em sua totalidade, a partir dos critérios: Ensaios Clínicos Controlados e Randomizados, originalmente em inglês, dos últimos 5 anos, envolvendo humanos, através da base de dados MedLine, sendo utilizada a escala prisma. A busca foi realizada mediante consulta ao MeSH e os descritores utilizados foram: "Acuteotitismedia", "prognosticfactors" e "otorhinolaryngology".

\section{REVISÃO BIBLIOGRÁFICA}

Foi observado uma resolução espontânea dos sintomas em pacientes com OMA entre 45 e $60 \%$ após o período de 10 dias em crianças acima de 2 anos, sendo a idade abaixo de 24 meses um dos principais indicadores de pior prognóstico. O uso de antibióticos se mostrou pouco efetivo no tratamento sintomatológico, porém parece estar associado a um menor número de complicações, principalmente perfuração timpânica e episódios de otite contralateral (VENEKAMP RP, et al., 2016).

Pacientes com abaulamento grave de membrana timpânica se beneficiam do tratamento antimicrobiano, uma vez que a falha terapêutica chega a $64 \% \mathrm{com}$ a ausência de seu uso neste grupo (TAHTINEN PA, et al., 2017). Indivíduos portadores de Síndrome de Down e crianças com Fenda palatina possuem maior risco a complicações, sendo o desenvolvimento de OMA recorrente mais frequente em tais pacientes (SHIELDER AGM, et al., 2017).

\section{CONSIDERAÇÕES FINAIS}

A Otite Média Aguda, mesmo com alta taxa de sucesso terapêutico, pode evoluir com graves complicações e eventuais sequelas. Idade menor que 24 meses, ausência de terapia antimicrobiana, 
gravidade do abaulamento da MT e presença de anormalidades craniofaciais mostraram-se como os principais fatores prognósticos para a gravidade da doença.

\section{REFERÊNCIAS}

1. SCHIELDER AGM, et al. Painel 7: Otite Média: Tratamento e complicações. SAGE journals, 2017; 156 (4S): S88-S105.

2. TAHTINEN PA, et al. PrognosticFactors for TreatmentFailure in AcuteOtitis Media. Pediatrics, 2017; 140(3). E20170072.

3. VENEKAMP RP, et al. Antibiotics for acuteotitis media in children. Cochrane DatabaseofSystematic Reviews, 2016; 6: CD000219. 
RESUMO SIMPLES: Revisão Bibliográfica

Título: O impacto do implante coclear na função cognitiva de pacientes idosos com perda auditiva

Autor/coautores: Olívia Féres Varela ${ }^{1}$, Miguel Eduardo Guimarães Macedo², Laura Ribeiro Galhardo Brun ${ }^{1}$, Breno Veggi Godinho ${ }^{3}$, Renato Cabral Pentagna ${ }^{3}$.

Instituição: ${ }^{1}$ Faculdade de Medicina do Centro Universitário Presidente Antônio Carlos (UNIPAC), Juiz de Fora - MG; ${ }^{2}$ Universidade Federal de Juiz de Fora (UFJF), Juiz de Fora - MG; ${ }^{3}$ Faculdade de Medicina da Faculdade de Ciências Médicas e da Saúde de Juiz de Fora (FCMS/JF), Juiz de Fora - MG.

Palavras-chave: Idosos, Cognição, Implante coclear.

\section{INTRODUÇÃO}

A expectativa de vida da população está aumentando e, com isso, a prevalência da perda auditiva se acentua, pois $30 \%$ de todas as pessoas com mais de 65 anos apresentam danos auditivos (VÖLTER C, et al., 2020). A perda auditiva entre os idosos é um fator preditor de incidência do declínio cognitivo, indivíduos com comprometimento auditivo possuem taxa de piora da capacidade cognitiva de $40 \%$ comparado àqueles com audição normal. O implante coclear (IC) fornece estímulo elétrico ao nervo auditivo e pode impactar positivamente na cognição de pacientes idosos (COSETTI MK, et al., 2016).

\section{OBJETIVO}

Revisar a literatura científica acerca do impacto na função cognitiva a longo prazo após reabilitação auditiva com IC em pacientes idosos com deficiência auditiva, a fim de verificar sua eficácia.

\section{MÉTODO}

Revisão sistemática onde foram analisados estudos originais, publicados originalmente em inglês, nos últimos 5 anos, tendo como referência a base de dados PubMed, com os seguintes descritores: "cochlear implant"; "Hearing Aids"; "Deployment Cochlear". A busca resultou em 136 artigos e foram selecionados 22, os critérios de inclusão foram: intervenção com implante coclear e cognição como desfecho do implante. Foram excluídos artigos que apresentaram divergências quanto ao objetivo do estudo.

\section{REVISÃO BIBLIOGRÁFICA}

As evidências científicas corroboram com mudanças significativamente positivas na função cognitiva de pacientes idosos com deficiência auditiva submetidos a reabilitação com IC e resultou na melhora da percepção da fala, dos domínios verbais, funções executivas (como atenção e memória de trabalho), percepção auditiva, memória de curto e longo prazo, nível de depressão e em uma melhor qualidade de vida; tais mudanças foram observadas em um período de 6 a 12 meses e se mantiveram estáveis após esse tempo.

Não foi verificada correlação entre os resultados cognitivos e o tempo e grau da perda auditiva (VÖLTER C, et al., 2018). Em um dos estudos, de 31 pacientes com comprometimento cognitivo leve antes do IC, $32 \%$ voltaram à cognição normal, $61 \%$ permaneceram estáveis e apenas $6 \%$ desenvolveram demência; nenhum dos 38 com capacidade cognitiva normal desenvolveu demência durante o acompanhamento, constatandose uma baixa taxa de progressão para demência após IC (MOSNIER I, et al., 2018).

\section{CONSIDERAÇÕES FINAIS}


A reabilitação auditiva com IC mostrou eficácia a longo prazo na melhora da função cognitiva dos idosos com diferentes graus de declínio auditivo, reduziu a incidência de demência e contribuiu para uma melhor qualidade de vida, devendo ser fortemente considerada nos indivíduos que possuem indicação para tal.

\section{REFERÊNCIAS}

1. COSETTI MK, et al. Neurocognitive testing and cochlear implantation: insights into performance in older adults. Clinical Interventions in Aging, 2016; 11: 603-613.

2. MOSNIER I, et al. Long-Term Cognitive Prognosis of Profoundly Deaf Older Adults After Hearing Rehabilitation Using Cochlear Implants. Journal of the American Geriatrics Society, 2018; 66(8): 1553-1561

3. VÖLTER C, et al. Benefits of Cochlear Implantation in Middle-Aged and Older Adults. Clinical Interventions in Aging, 2020; 15: 1555-1568.

4. VÖLTER C, et al. Can cochlear implantation improve neurocognition in the aging population? Clinical Interventions in Aging, 2018; 13: 701-712. 
RESUMO SIMPLES: Estudo Original

Título: Principais achados da videoendoscopia em pacientes com esclerose amiotrófica

Autor/coautores: Isadora Soares Lopes ${ }^{1}$, Maria Paula Ribeiro Dantas Bezerra ${ }^{1}$, Larissa Melo Silva ${ }^{1}$, Mônica Claudino Medeiros Honorato², Lidiane Maria De Brito Macedo Ferreira ${ }^{3}$.

Instituição: ${ }^{1}$ Acadêmica de Medicina da Universidade Federal do Rio Grande do Norte (UFRN), Natal - RN; ${ }^{2}$ Residente em Otorrinolaringologia no Hospital Universitário Onofre Lopes (HUOL), Natal - RN; ${ }^{3}$ Professora do Departamento de Cirurgia.

Palavras-chave: Transtornos de deglutição, Esclerose amiotrófica lateral, Endoscopia.

\section{INTRODUÇÃO}

Esclerose Lateral Amiotrófica (ELA) é uma doença neurodegenerativa caracterizada pela disfunção do neurônio motor superior e inferior (LENGLET T e CAMDESSANCHÉ JP, 2017). Seu quadro clínico é variável, porém, quando o tronco cerebral é afetado, os músculos responsáveis pela fala, mastigação e deglutição atrofiam, de modo que a disfagia é um sintoma frequente à maioria dos pacientes durante a progressão da doença e pode resultar em complicações, desde pneumonias aspirativas ao prejuízo na qualidade de vida (FATTORI B, et al., 2017; BRANDAO BC, et al., 2019). A videoendoscopia da deglutição (VED) é uma das formas de avaliar a funcionalidade da deglutição nesses pacientes e progressão da doença.

\section{OBJETIVO}

Analisar os principais achados clínicos do exame de nasofibrolaringoscopia da deglutição em pacientes com diagnóstico de esclerose Lateral Amiotrófica (ELA). Além de descrever a frequência das alterações na deglutição nesses pacientes.

\section{MÉTODO}

Estudo retrospectivo com análise dos prontuários de pacientes atendidos no Ambulatório de Disfagia do Hospital Universitário Onofre Lopes entre 2018 e 2020, diagnosticados com ELA e VED realizada para avaliação de disfagia. Estudou-se os laudos para descrever os achados da Escala Funcional de Ingestão Oral (FOIS, em inglês) e avaliação do risco nutricional com o Nutritional Risk Scale (NRS-2002). Trabalho aprovado pelo CAAE sob número 97285118.9.0000.5292.

\section{RESULTADOS}

Entre 2018 e 2020, foi realizado o exame em 26 pacientes com diagnóstico de ELA, dos quais 17 (65\%) tinham FOIS 5-6. Os principais achados foram: 19 (73\%) pacientes evidenciaram presença de resíduos, dos quais 10 foram classificados como grau leve. As alterações de sensibilidade ocorreram em 08 pacientes, penetração em 09 (34\%) e aspiração em apenas 05 (19,2\%) pacientes.

Sete indivíduos realizaram deglutições múltiplas. $O$ início da resposta faríngea para deglutição ocorreu nas valéculas em 18 pacientes e o escape oral posterior foi revelado em vinte. A mobilidade das pregas vocais estava preservada na maioria dos pacientes (92,3\%). Houve risco de comprometimento nutricional em 05 pacientes.

\section{CONSIDERAÇÕES FINAIS}


Dentre as alterações encontradas em pacientes com ELA avaliados pela VED, 13 foram classificados como disfagia leve, 06 moderada, 04 graves e dois deglutição normal. Alterações mais prevalentes foram: presença de algum grau de resíduo, escape oral posterior, penetração e alterações de sensibilidade. A aspiração associa-se a complicações graves estando presente na minoria. Esses distúrbios necessitam detecção para minimizar prejuízos funcionais e promover melhora na qualidade de vida.

\section{REFERÊNCIAS}

1. BRANDAO BC, et al. Relationship between oral transit time and functional performance in motor neuron disease. Arq. Neuro-Psiquiatr, 2019, 77(8): 542-549.

2. FATTORI B, et al. Dysphagia in Amyotrophic Lateral Sclerosis: Relationships between disease progression and Fiberoptic Endoscopic Evaluation of Swallowing. Auris Nasus Larynx, 2017; 44(3): 306-312.

3. LENGLET T, CAMDESSANCHÉ JP. Amyotrophic lateral sclerosis or not: Keys for the diagnosis. Rev Neurol (Paris), 2017; 173(5): 280-287. 


\section{AGRADECIMENTOS}

\section{Financiamento}

Universidade Federal de Juiz de Fora (UFJF) e Hospital Evandro Ribeiro, pelo apoio institucional e certificação acadêmica do evento.

\section{Patrocinadores}

Hospital Evandro Ribeiro.
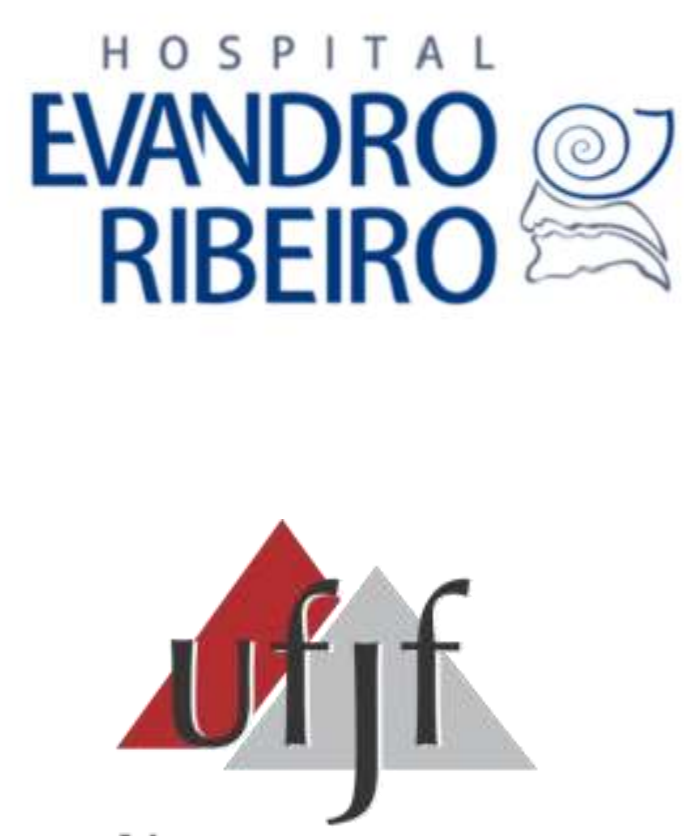

UNIVERSIDADE

FEDERAL DE JUIZ DE Fora 